\title{
Abrevia su hermosura virgen rosa: \\ En torno a un símil de la Soledad primera
}

\author{
Jesús Ponce Cárdenas* \\ Universidad Complutense de Madrid \\ jmponce@ucm.es
}

Recepción: 23/02/2021, Aceptación: 23/03/2021, Publicación: 22/12/2021

\begin{abstract}
Resumen
El presente estudio examina un pasaje de la Soledad primera a la luz de las prácticas de la imitatio. En el análisis del símil de la rosa se identifica el modelo subyacente (una comparación engastada en un soneto laudatorio de Torquato Tasso) así como algunos procedimientos de ocultamiento y potenciación expresiva característicos de la praxis gongorina.
\end{abstract}

Palabras clave

Góngora; Soledad primera; símil; rosa; Torquato Tasso; imitación; agudeza; epitalamio.

\begin{abstract}
English Title. Abrevia su hermosura virgen rosa: Considerations on a Simile in Góngora's Soledad primera.

Focusing on the practice of poetic imitation, this study examines a fragment of Góngora's Soledad primera. Through the analysis of the rose-simile we will identify the hidden model (a comparison set in a laudatory sonnet by Torquato Tasso) as well as some procedures of concealment and stylistic enhancement used by the Cordoban writer.
\end{abstract}

Keywords

Góngora; Soledad primera; simile; rose; Torquato Tasso; imitation; wit; epithalamium.

* El presente artículo se inscribe en el marco del Proyecto "Hibridismo y Elogio en la España Áurea” (HELEA PGC2018-095206-B-I00), financiado por el Ministerio de Ciencia, Investigación y Universidades y el Fondo Europeo de Desarrollo Regional FEDER. Agradezco a mis compañeros de proyecto Mercedes Blanco, Pedro Conde Parrado y Juan Matas Caballero la atenta lectura del 
Las Soledades ofrecen uno de los ejemplos más refinados y complejos de hibridismo en la historia de la literatura española. Sobre este particular, varios estudios recientes han puesto de relieve cómo en la hermética obra confluyeron géneros tan dispares como la epopeya didáctica y el epitalamio, la poesía piscatoria y el epinicio, la égloga y el epilio. ${ }^{1}$ Bajo la enseña de la imitación ecléctica, Góngora compuso el ambicioso poema narrativo engastando a lo largo de sus dos partes infinidad de teselas provenientes de todo tipo de modelos. ${ }^{2} \mathrm{~A}$ zaga de los comentaristas antiguos, algunos especialistas contemporáneos han estudiado con atención la pléyade de autores que sirvieron como dechado al poeta cordobés, tanto clásicos (Virgilio, Horacio, Ovidio, Estacio, Claudiano, Opiano, Nono de Pannópolis...) como modernos (Pontano, Garcilaso de la Vega, Ariosto, Bernardo Tasso, Luigi Tansillo, Torquato Tasso, Gabriello Chiabrera, Giovan Vincenzo Imperiale...). Las reminiscencias de autores grecolatinos, neolatinos e italianos estaban vinculadas bien a la lectura directa de sus obras poéticas y al personal trabajo de conformación del codex excerptorius o cartapacio, bien a la consulta de repertorios que brindaban un acceso inmediato a esa misma información erudita, pero ya cribada y sistematizada. Por ejemplo, en el campo de la elocutio gongorina, se ha demostrado en un brillante estudio cómo Góngora accedió a un ingente caudal de calificativos y de iuncturae latinas y neolatinas a través de una compilación enciclopédica: los Epitheta del humanista francés Ravisio Textor (Conde Parrado 2019b). Conviene recordar que también desde el terreno de las letras vernáculas existían obras de consulta similares, como el Tesoro di concetti poetici de Giovanni Cisano, cuyo posible manejo por parte de los escritores áureos no se ha sondeado todavía. ${ }^{3}$

original de este trabajo, así como los consejos y anotaciones que me han brindado. Mi gratitud se hace extensiva a los dos atentos revisores del artículo.

1. Espigo a continuación algunos trabajos recientes sobre tales aspectos genológicos: Blanco (2012, 2014, 2016, 2020), Tanabe (2011), Ponce Cárdenas (2013, 2014a, 2020).

2. Como generosamente me apunta Mercedes Blanco, resultaría conveniente prescindir de la identificación reductiva de las Soledades como una composición meramente descriptiva, pues "aunque contenga descripciones, su propósito es contar algo. Un poema descriptivo es la Descripción de La Tapada de Lope de Vega o ciertas silvas de Estacio cuyo propósito es describir un lugar o una cosa reales (o que se hacen pasar por reales). La dimensión temporal de las Soledades cuenta mucho: el tiempo pasa y hay diversas acciones, se producen encuentros, se llevan a cabo ritos, se perciben movimientos. Otra cosa es que el ritmo del poema, su tempo, sea lento y que lo que cuenta carezca de dramatismo".

3. El largo título de la obra clarifica la índole compilatoria sin ambages: Tesoro di concetti poetici scelti da' più ilustri Poeti Toscani e ridotti sotto capi per ordine d'alfabeto da Giovanni Cisano. Con annotationi in molti luoghi di diversi, nelle quali si mostrano i colori et ornamenti poetici, i lumi delle dottrine e dell'arti sparsi per entro i detti concetti et i luoghi tolti da' Poeti Greci et Latini et felicemente imitati da' nostri. Oltre di ciò sotto i medesimi capi sono ridotti i concetti espresssi nelle Imprese raccolte in diversi volumi da diversi autori, con le loro dichiarationi e discorsi (1610). Los dos volúmenes del Tesoro de conceptos poéticos de Cisano no solo ofrecían una selección de pasajes de los grandes maestros de la poesía italiana sino que además incorporaban comentarios a dichos fragmentos y anotaciones sobre las fuentes antiguas en las que se inspiraban tales versos. 
Siguiendo esa estela comparatista, el propósito de este artículo es examinar en profundidad un símil inserto en la sección epitalámica de la Soledad primera: la comparación de la novia aldeana con una rosa que comienza a entreabrirse. Para atender a todos los posibles matices de esta figura y su engaste en la obra, el presente estudio se dividirá en cinco apartados. En primer lugar se determina el contexto narrativo que rodea a la incorporación de dicho símil. Seguidamente se pasa revista a la aportación de los comentaristas áureos y la visión que dan de la imagen floral. En el tercer apartado se propone un nuevo hipotexto: un fragmento de Torquato Tasso que es la fuente probable del pasaje, aunque pasó desapercibido a los eruditos del siglo XVII. La sección cuarta se centra en el comentario de varios rasgos elocutivos, en especial de la llamativa selección léxica, que genera una ruptura en el horizonte de expectativas, dado que no responde plenamente a los criterios estéticos más extendidos a inicios de la centuria. El sello de la agudeza, perceptible en el entero ejercicio de rescritura, constituye el asunto del último apartado.

\section{Veteris vestigia pudoris: rubor épico y recato epitalámico}

$\mathrm{Al}$ inicio mismo del fragmento nupcial de la Soledad primera, Góngora disponía en el escenario arcádico y sencillo de las bodas aldeanas a varios personajes, aportando diferentes notas sobre los mismos. Mediante la adjetivación se caracteriza en el relato a cada una de las tres figuras que concurrían ante el innominado protagonista. Acompañado por su montaraz guía, el peregrino acude ante los anfitriones del festejo nupcial y con toda cortesía es presentado: primero al futuro esposo, del que se pondera con una rápida pincelada el porte y bizarría ("galán novio"); después al padre de la joven, que destaca por su distinción y respetabilidad ("venerable padre"); por último, a la novia ("bella", "dulce", "afable"), en la que el recato y la hermosura juvenil corren parejas. ${ }^{4}$ La escena se describe en los siguientes términos (vv. 722-731):
Al galán novio el montañés presenta
su forastero, luego al venerable
padre de la que en sí bella se esconde
con ceño dulce y, con silencio afable,

4. De hecho, Manuel Serrano de Paz establece una suerte de jerarquía en el grupo de personajes y precisa que en el orden de presentación se ha seguido una segura etiqueta: "En el matrimonio hay personas principales y hay adjuntas: aquellas son los novios, estas los suegros y los parientes. Entre aquellas tiene lugar primero el esposo y así ante él presenta lo primero el montańés al peregrino y luego ante el suegro. Llama galán al novio, en quien incluye las gracias de mozo, bizarro y bien dispuesto" (f. 494v). Prosigue después la anotación sobre el sentido del mismo epíteto ponderativo: "Galán le llama también, que es lo mismo que bien proporcionado y fuerte de miembros, grande don en los varones, como dijo Bión: 'Forma mulieres ornat, uirum autem robur'" (f. 495r). 
beldad parlera, gracia muda ostenta, cual del rizado verde botón, donde abrevia su hermosura virgen rosa, las cisuras cairela un color que la púrpura que cela por brújula concede vergonzosa.

(Góngora, Soledades, ed. R. Jammes, pp. 343-345)

Una vez dispuestos los personajes en el escenario nupcial, puede verse cómo dentro del relato el novio y el padre no suscitan mayor atención, en tanto que la muchacha a punto de desposarse se erige en objeto de especial interés por su timidez y belleza. Se introduce entonces un símil extendido que Góngora va a dilatar de manera notable a lo largo de ocho versos: los tres primeros endecasílabos se reservan para el elemento real o término base (la novia pudorosa que permanece en silencio) en tanto que los cinco versos siguientes los ocupa el término de comparación (la rosa que comienza a despuntar y no deja contemplar del todo el esplendor de sus pétalos carmesíes, encerrados aún en el verde botón). ${ }^{5}$ Como indicaba Robert Jammes, "la finalidad primera de esta comparación es, según la lógica de la retórica tradicional, ponderar el pudor juvenil, la hermosura todavía en ciernes de la novia. Pero finalmente lo que queda en la memoria del lector es un elemento más de su visión poética de la naturaleza" (Jammes 1991: 217).

Antes de acometer el análisis detallado del parangón floral y la tradición poética en el que se inscribe, conviene reflexionar brevemente sobre las notas acerca de la actitud, el carácter y el físico de la figura femenina que sutilmente moldea el relato. El primer comentarista que atendió a algunos detalles significativos en el pasaje fue Pedro Díaz de Rivas (1587-1653) en sus conocidas Anotaciones y defensas a la Primera Soledad (BNM, Ms. 3726, f. 154r-v):

152. En sí bella se esconde. Con increíble venustidad y elegancia significa la modestia virginal y el vergonzoso encogimiento de la novia; el cual parece ocultaba su belleza y como por brújula la mostraba. Ella, pues, debajo de un ceńo dulce y un silencio afable mostraba una belleza o beldad parlera y una gracia muda. Es la modestia y vergüenza un don muy grande en las mujeres. Especialmente se suele hallar en las doncellas desposadas. ${ }^{6}$ Así dijo Homero, libro VI Odisea hablando de la hija de Alcínoo, rey de los Feacios: "Uerecundata est nouas nuptias nominare". ${ }^{7}$ Virgilio, li-

5. Sobre el símil en la Fábula de Polifemo y Galatea puede consultarse Ponce Cárdenas (2009: 241-369).

6. Tanto Pedro Conde Parrado como yo estimamos que esta frase es una cuasi-traducción del fragmento que introduce el pasaje de Tiraqueau que luego se va a citar. Ello supondría de por sí un indicio bastante claro de que tal era su fuente.

7. El breve pasaje de la Odisea citado en versión latina se localiza en el libro VI, vv. 66-67: "ஸ்

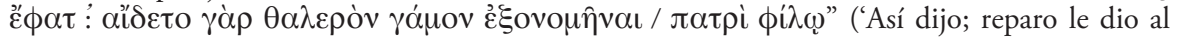
nombrar ante su padre la sazón de sus bodas'). En la difundida traducción latina de Raffaele di 
bro XII, Aeneis introduciendo a Latino y Amata, que trataban del casamiento de Lavinia, finge que Lavinia calla y se avergüenza: "Accepit nocem lacrymis Lavinia matris, / flagrantes perfusa genas, cui plurimus ignem / subiecit rubor". ${ }^{8}$ Tibulo libro [III] "Ut iuneni primum uirgo deducta marito, / inficitur teneras ore rubente genas".?

Como han mostrado varios estudios recientes (Conde Parrado 2017, 2018, 2019a , 2019b, 2020), en el Siglo de Oro, los repertorios de información que permitían acceder a una selección de excerpta antiguos eran de muy varia índole. Para el caso específico de esta glosa de Pedro Díaz de Rivas, se puede plantear la posibilidad de que no estuviera manejando directamente una de las varias traducciones latinas de la Odisea que circulaban por Europa desde el Quinientos y que tampoco hubiera ojeado en esta ocasión precisa cualquiera de las múltiples ediciones de la epopeya virgiliana.

A la luz de la versión en latín de los hexámetros griegos que se citan en el pasaje, cabría sospechar que el comentarista gongorino pudo tener acceso a los mismos y al fragmento virgiliano mediante la consulta de un tratado sobre derecho matrimonial del humanista y jurisperito francés André Tiraqueau (14881558): De legibus connubialibus et iure maritali. ${ }^{10}$

Volterra el fragmento rezaba así: (libro VI) "Sic ait erubuit enim matrimonium manifeste nominare apud patrem”. Odissea Homeri per Raphaelem Volaterranum in latinum conuersa, Romae, Per Iacobum Mazochium, 1510, s. f. Cabe sospechar, por otro lado, que la versión latina del pasaje homérico parece deberse al propio jurista francés.

8. Virgilio, Eneida, 'Escucha Lavinia las palabras de su madre con las ardientes mejillas llenas de lágrimas, pues un rubor intenso abrasa y se difunde al punto por su encendido semblante'.

9. Tibulo, Elegía III, 4, vv. 31-32 'como cuando una muchacha, conducida por vez primera ante su joven esposo, tińe con el rubor en su semblante las tiernas mejillas'.

10. Desde su publicación en las prensas de Lyon en 1546 la obra tuvo una aceptación notable, lo que se tradujo en varias reimpresiones $(1554,1560,1574,1575)$ que gozaron de bastante difusión por toda Europa. Por ejemplo, sobre la distribución de la misma en España, téngase en cuenta que el mismo tratado se cita en la Soledad primera ilustrada y defendida como fuente de información para todo tipo de asuntos relacionados con las bodas en el mundo clásico: "De manera que según esta sentencia (que en parte la tengo por más verdadera) sería la novia de quince años, edad competente para el matrimonio, como lo trata Tiraquello in lege VI Connubialibus, ${ }^{\circ}$ 40 et lege VII, no 39"; "Así llamaron a Diana uerecunda, como lo prueba Tiraquello in lege IX Connubialibus, por ser en las doncellas muy ordinaria, particularmente cuando se trata de casarlas"; "Y así para el casamiento era mal agüero el mes de mayo [...]. La causa de ello dan Tiraquello, libro VI Connubialibus, no 14; Brisonio, De ritu nuptiarum, IV, capítulo 2 et libro II, capítulo 5 y otros"; "Aristóteles en su Política, capítulo 17, prohíbe toda suerte de pintura deshonesta y así lo da por precepto Tiraquello, libro XVI Connubialibus" (Góngora vindicado. Soledad primera ilustrada y defendida, pp. 328, 334, 340, 354). Por otro lado, como me recuerda generosamente Pedro Conde Parrado, también cita varias veces a Tiraquello Salazar Mardones en la Ilustración y defensa de la fábula de Píramo y Tisbe (ff. 42r, 111r, 119r, 157v, 160v, 178v), aunque no siempre se refiera allí a su obra sobre el matrimonio. En el f. 42r por ejemplo sí se refiere a esta obra sobre las leyes matrimoniales y, curiosamente, da también un ejemplo procedente de Homero extraído de la misma (aunque Salazar Mardones sí lo admite abiertamente, no como Díaz de Rivas). 
qui naturalem pudorem afsignat mulieribus. Et l..n coniun $C$ tione, in illis verbis, \& fi puella cultu verecundix,\&c.C.de nup.vbi no. Bal.quòd naturale eft mulieri,pró pter verecundiam tacere. Et ca quidem l. loquitur de puella, qux pr $x$ verecundia de nuptiis fuis interrogata fubticet. Quam \& puellarum naturam mirè exprefsit Homerus lib. Odyffex 6.loquens de Nauficaa Alcinoi Phxacum regis filia:

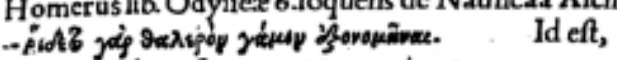

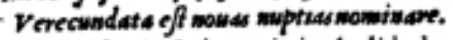

Et Euripides in Iphigenia in Aulide, loquens de puellis:

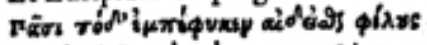

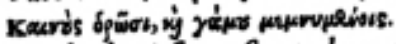

Omibus hoc infitum oft, rt pudore ceppientur, swicos

Nowos videnteser muprianum recordantes.

is 9 Quos fecutus Virgilius, paulò poft principium li.12.Aeneidos, Latinum, \& A ma tam vxorem cum Turno colloquentes facit de coniugio ipfus cum Laninia corum filia:at Lauiniam ipfam interim loquentemnon facit, fed tantùm dat ci lacrymas, \& pudorem:

\section{Mecepit vocem laciomin Laviwia matris \\ Flograntes perfufagends, cui plurimus ignem \\ subiecit rubaryo catera. \\ Quo in loco Chriftophorus Landinus interpres,id non infcitè annotauit.Augufti nus autem de Verbis domini,fermone 46.Vxorem (inquit) refræenat infirmicatis}

Figura 1

\section{De legibus connubialibus et iure maritali, Lugduni, Apud Gullielmum Rovilium, 1560, f. 153r.}

El apartado de la obra que pudo llamar la atención del erudito cordobés se abría con las ideas siguientes: "Naturale est mulieri propter verecundiam tacere. Et ea quidem lex loquitur de puella, quae prae verecundia de nuptiis suis interrogata subticet" ("Es algo natural en las mujeres guardar silencio a causa de la vergüenza. Y esa ley, ciertamente, habla de la doncella que, al ser preguntada por sus bodas, calla por pudor'). Poco después, el estudio de Tiraqueau recogía puntualmente las dos citas aducidas por Díaz de Rivas en la nota 152, precisamente en un apartado en el que la entera reflexión se iba a centrar en "la verecundia" o el "recato de las muchachas cuando se habla de sus matrimonios". ${ }^{11}$ El humanista

11. Nótese también la proximidad en algunas expresiones: "Uerecundia puellarum cum tractatur de nuptiis earum" / "Es la modestia y vergüenza un don muy grande en las mujeres. Especialmente se suele hallar en las doncellas desposadas". Por otra parte, conviene recordar asimismo que Pedro Díaz de Rivas a menudo consultó con provecho los comentarios a Virgilio del padre Juan Luis de la Cerda, tal como demostraron ejemplarmente Melchora Romanos y Patricia Festini en la reciente edición electrónica de las glosas del erudito cordobés a la Soledad segunda. Puede consultarse en red en <https://obvil.sorbonne-universite.fr/corpus/gongora/1617_soledadsegunda-diaz>. 
galo pondera además la certera visión que daba Homero sobre el asunto: "et puellarum naturam mire expressit Homerus" ('y Homero expresó de manera admirable la naturaleza de las doncellas').

Más allá de la procedencia de estos retazos eruditos, considero que el contenido de la nota 152 presenta algunos relieves interesantes, no tanto porque acierte o falle al proponer la cercanía de los versos gongorinos a un modelo clásico concreto, sino más bien por lo que sus glosas revelan acerca de la estimativa en torno a los géneros antiguos y, sobre todo, por la actitud y gestos que son propios de una tipología concreta de personaje en un contexto determinado. ${ }^{12}$

A todas luces, el erudito cordobés creyó identificar en el pasaje gongorino una situación específica: en un contexto de hospitalidad arcaica, una bella joven es presentada a un invitado extranjero, hallándose junto a ambos el padre de la doncella. Como describe la silva, la actitud de la muchacha es inequívoca: por timidez y recato la novia no profiere palabra alguna y se sonroja. De entre todos los posibles paralelos de la historia de la literatura universal que podría haber elegido, Díaz de Rivas se fija, ante todo, en dos cimas de la poesía de Occidente y trata de establecer así un vínculo silencioso entre la inconclusa obra maestra de Góngora y los venerables modelos de la épica grecolatina. Del tratado humanístico sobre derecho nupcial pudo quizá haber extraído dos pasajes de la Odisea y la Eneida, en los que Nausícaa y Lavinia, respectivamente, se ruborizan cuando se saca a colación el argumento de las bodas, al tiempo que desecha la cita de Eurípides. Al lado de los pasajes de ambas epopeyas Díaz de Rivas también evocará un ejemplo del entorno amatorio-elegíaco (Tibulo) que no figura en la obra de Tiraqueau.

A la luz del intento de vinculación del pasaje con la épica por parte de Díaz de Rivas, conviene prestar similar atención al hipotexto que algunos años más tarde propusiera don García de Salcedo Coronel (Soledades comentadas, f. 153r-v):

Presentó el montañés su huésped al galán novio y luego le llevó al venerable padre de la desposada, que hermosa se escondía en su virginal recato con dulce ceño y ostentaba con afable silencio una belleza elocuente y una gracia muda. Imitó nuestro poeta esta hermosa descripción de Estacio, libro II Tebaida, donde hablando de

12. Puede verse también la información recogida por Cisano en el Tesoro di concetti poetici bajo las entradas "Vergine" (II, pp. 983-986) y "Vergogna" (II, pp. 986-992). Entre los pasajes poéticos allí aducidos se localizan el símil de la rosa incluido por Ariosto en el canto primero del Orlando furioso, la comparación con la flor del epitalamio de Catulo, el mismo parangón catuliano imitado por Battista Guarini en Il pastor Fido (acto I, escena cuarta) y los cuartetos del soneto Negli anni acerbi tuoi purpurea rosa (con las variantes propias de su segundo estadio de redacción). Téngase en cuenta que la primera versión de estos últimos endecasílabos ya la había recogido Giovanni Cisano en la primera parte del Tesoro, bajo la voz "Gioventú" (I, p. 998). Por otro lado, el largo símil de la rosa engastado por Tasso en una canción dialogada se reproducía en el tomo primero, en la entrada que dedica a la acción de "Innamorarsi" (I, 1089). Igualmente cabe constatar que el parangón tassesco de la rosa "modesta e verginella" que figura en el canto XVI de la Gerusalemme liberata también se reproduce en la entrada que dedica a "Persuadere ad amare" (I, p. 140). 
Argia y Deífile dice: "Ibant insignes uultuque habituque uerendo, I candida purpureum fusae super ora pudorem / deiectaeque genas; tacite subit ille supremus / uirginitatis amor, primaeque modestia culpae / confundit uultus". ${ }^{13}$

El fragmento aducido por el caballero hispalense forma parte de uno de los mejores poemas épicos de la Edad de Plata latina: la Tebaida. En un pasaje del libro segundo se describe el inicio de la ceremonia de las dobles nupcias de Argia y Deífile con Polinices y Tideo. Como muestran los hexámetros, la belleza y el rubor, el silencio y el decoro identifican a las dos figuras femeninas.

Por último, conviene traer a la memoria el testimonio de Manuel Serrano de Paz. Entre sus interesantes comentarios manuscritos, conservados en dos gruesos volúmenes, la glosa consagrada a este pasaje se distancia algo de las apostillas firmadas por sus predecesores. En efecto, el erudito radicado en Oviedo no quiso remitir a pasaje épico alguno y se inclinó por otro tipo de escritura celebrativa, proponiendo otra posible reminiscencia estaciana:

Parece que imitó esta vergüenza bella y ceño dulce en Estacio libro I Silvas in Epithalamio: "Ipsa manu nuptam genetrix Aeneia duxit / lumine demissam et dulci probitate rubentem" ${ }^{14}$ Estaba la serrana con los ojos bajos, pero no era el ceño torcido, ni feo, sino dulce ceño, que no espantaba, antes atraía (f. 496r).

La anotación de Serrano de Paz no pone de relieve ningún paralelo con el género sublime por excelencia, sino que centra toda su atención en la actitud de una tímida novia en el marco laudatorio del epitalamio. ${ }^{15} \mathrm{La}$ beldad aldeana de las Soledades y la hermosura de Violentila ostentan, a sus ojos, una gracia y un pudor afines. Con suma finura, aprecia Mercedes Blanco que la iunctura estacia-

13. Tebaida, II, vv. 230-234 (ed. G. Faranda Villa, pp. 138-140). En la traducción secentista de Juan de Arjona dice así el pasaje: "Las dos, entre casadas y doncellas, / venerables de rostro y de vestido, / callando están y sus mejillas bellas / de un rosado color se habían teñido, / que aumenta más la hermosura de ellas, / aunque es color de su temor nacido; / fe cierta, último amor, secreta nube / de su virginidad, que al rostro sube" (I, p. 79).

14. Silva I, 2, vv. 11-12 (ed. R. Shackleton Bailey, p. 40). 'La madre de Eneas en persona ha traído de la mano a la novia, que baja los ojos y se ruboriza con dulce candidez'.

15. Martín Vázquez Siruela -como generosamente me recuerda Pedro Conde Parrado- también remitiría a Estacio (en concreto a los dos versos de la silva I, 2 recogidos en la nota precedente) a propósito del sintagma ceño dulce. Pellicer, por su parte, se limitó a realizar una mera paráfrasis de los versos gongorinos: "Llegó el anciano a presentar el forastero al bizarro novio, luego al padre de la desposada, que con ceño apacible y con silencio afable se escondía, como no hablaba vergonzosa, dentro de su mismo empacho. Estaba graciosamente muda, pero con hermosura muy elocuente, del modo mismo que la virgen rosa en el capullo rizado en el botón verde, donde encoge su resplandor, descubriendo un breve cairel de púrpura, por donde comienza a abrirse, de modo que ofrece por brújula la púrpura misma que cela, así la desposada encogía dentro de su vergüenza lo más hermoso de sus gracias concediendo escasamente un rasguño de lo que encubría” (Pellicer, Lecciones solemnes, col. 492). Frente a la aportación de los demás comentaristas, que intentan identificar con acribia una o varias fuentes posibles de la comparación, el cronista real no dedicó esfuerzo alguno a la dilucidación de los hipotextos del pasaje. 
na "dulci probitate" podría hacer gala, en términos horacianos, de una cierta calliditas, pues el epíteto forma con el núcleo nominal una combinación algo sorprendente. El sustantivo latino probitas se refiere a la 'rectitud', la 'honradez', la 'lealtad', la 'integridad' o las 'buenas costumbres' y por tanto hace pensar en "una cierta severidad" o un exigente rigor, elementos que no resultan del todo "acordes con la dulzura". A la luz de tal detalle, sería plausible identificar como origen (bastante verosímil) del sintagma gongorino "dulce ceño" la juntura de Estacio "dulci probitate": en primer lugar, por la equivalencia verbal del mismo epíteto, localizado en ambas troquelaciones; en segundo término, por el efecto afín de extrańamiento que estas callidae iuncturae ponen en juego. De hecho, Góngora intensificaría la sugestión estaciana, dado que convierte el sintagma en un verdadero oxímoron. Un lector atento percibe cierto extrańamiento en la aplicación del adjetivo "dulce" a un vocablo tan marcado como "ceño", ya que este designa "un modo de mirar severo y desabrido, abajando las cejas", propio de "los mal contentos y los envidiosos" y de todos "aquellos que no les da gusto aquello que miran" (Covarrubias, Tesoro de la lengua, p. 406).

En verdad, los textos que Díaz de Rivas, Salcedo Coronel y Serrano de Paz esgrimieron como posibles paralelos antiguos para el término real de la comparación no plantean ninguna equivalencia verbal obvia. Parece dudoso (o cuanto menos indemostrable) que Góngora tuviera que acudir forzosamente a las fuentes allí señaladas o a otras similares. Sin embargo, la información que proporcionan los tres eruditos no debe descartarse como algo inútil o superficial, pues de alguna manera nos pone sobre aviso: la escena pergeñada por Góngora se repite poéticamente desde el alba de los tiempos manifestando siempre una misma gestualidad, una actitud concordante, pues nos hallamos ante un estereotipo, es decir, ante una "imagen o idea aceptada por un grupo o sociedad con carácter inmutable" (RAE). El interés de tales anotaciones se revela así crucial desde el plano de las ideas o del contenido.

El testimonio de los comentaristas no solo sirve para dar noticia de teselas concretas que fueron sometidas a rescritura por Góngora según las pautas imitativas de la época, sino que también resulta muy útil para identificar estereotipos, lugares comunes, situaciones tópicas... ${ }^{16}$ Desde la Grecia antigua hasta la España barroca, pasando por la Roma clásica, la imagen de una doncella a punto de contraer matrimonio se asocia, de una forma casi atávica, con las ideas de la belleza juvenil y la virginidad, con las virtudes de la timidez y el pudor que acrecientan su gracia y atractivo. ${ }^{17}$

16. Baste pensar en el caudal de motivos y tópicos que identificó Antonio Vilanova (1992) en su magistral estudio sobre las fuentes y los temas del epilio gongorino, sumando a los datos extraídos de los comentaristas las novedades que afloraron a partir de sus propios descubrimientos.

17. Sobre la uerecundia como un valor principal en una joven esposa disertó largamente Manuel Serrano de Paz en sus Commentarios a las Soledades, con apabullante acopio de citas (Musonio, Cicerón, San Bernardo, Valerio Máximo, Quinto Curcio, Aristóteles...) no forzosamente de na- 
Al evocar en el poema a una hermosa joven a punto de casarse, de algún modo Góngora se vería compelido a caracterizarla siguiendo las normas de un decoro vigente desde el mundo antiguo. La bella adolescente que se encontraba en los "inciertos crepúsculos de su edad segunda" tenía que estar adornada con los dones de la hermosura y el recato, de acuerdo con esa suerte de unwritten rule. Góngora se pliega ante ese imperativo con toda naturalidad y, al actuar así, se inscribe en una larga cadena literaria que cuenta con diversos eslabones en la épica grecolatina, la elegía amatoria romana y el epitalamio de época flavia. Parece indudable que el autor de las Soledades no imita aquí expresamente ni a Homero, ni a Virgilio, ni a Tibulo, ni a Estacio. Las troquelaciones verbales de los cuatro maestros antiguos no parecen dejar una huella nítida en el término real de la comparación, según lo modela Góngora. Ahora bien, desde el plano de la res o la inuentio, los cuatro vates grecolatinos y el escritor barroco participan unánimemente de una misma visión, nos hablan de un único estereotipo, a la manera de un signo cultural inmutable.

\section{La rosa en los comentaristas antiguos}

La reflexión más notable sobre el símil de la rosa entre los comentaristas de Góngora fue la de Pedro Díaz de Rivas, ya que en una extensa glosa de sus Anotaciones fue desgranando todo un abanico de parangones de hermosura vinculados a aquella flor. En dicho elenco el erudito cordobés proponía hasta seis posibles loci paralleli, fijando su atención en un modelo tardo-antiguo (Claudiano), un dechado neolatino (Pontano), tres hipotextos italianos (Ariosto, Tasso, Marino) y uno español (Bartolomé Leonardo de Argensola):

153. Cual del rizado verde botón. Porque era virgen de pocos ańos y parece que ocultaba su hermosura con la modestia, la compara a una rosa que del todo no ha salido del capullo. Quizá es imitación de Claudiano In nuptiis Honorii et Mariae, hablando de una madre e hija: "uel flore sub uno / ceu geminae Paestana rosae per iugera regnant: / haec largo matura die saturataque uernis / roribus indulget spatio; latet altera nodo / nec teneris audet foliis admittere soles". ${ }^{18}$ Joviano Pontano, elegan-

turaleza poética. Comenzaba así su reflexión: “Tres cosas alababa Sócrates en la juventud: prudencia en el entendimiento, silencio en la lengua y vergüenza en la cara. Con estas dos últimas adorna el Poeta a esta novia y ambas nacían de su vergüenza, adorno mayor en las mujeres y más natural en ellas que en los hombres. Así dice que se esconde en sí misma, que estaba llena de vergüenza, y por eso escondida y recogida en sí misma [...]. Grande ha de ser en ellas la vergüenza, pues es la guarda de todas las virtudes, la que deshace cualquier infamia, la que acarrea todas las alabanzas. Sin ella nada hay bueno, nada honesto, nada loable" (f. 495r).

18. Claudiano, Epithalamium de nuptiis Honorii Augusti, vv. 246-250 (ed. J. L. Charlet, p. 75), 'o como en un mismo tallo dos rosas reinan entre los campos de Paestum: una ya madura a plena luz del día, empapada por el rocío primaveral, intenta abrirse; la otra se oculta en el botón y no se 
tísimo poeta, en sus Endecasilabos Ad Ariadnam uxorem: "Qualis floridulo nitens in horto I nondum puniceas comas reclusit, I et iam puniceas comas recludit I ac rarum decus explicare quaerit / quae laeto rosa ramulo refulget; / talis purpureis genis et ore, I ut quae non tenerum cupit maritum, I sed iam iam tenerum cupit maritum, / cui prima oscula dedicet suumque / florem uirginei dicet pudoris / suspirans uiduo puella lecto, I fulgebas mihi primulosque amores / spirabas oculis [sinuque blando / afflabas Arabum suos odores, / fundebas Charitum suos honores, I et laetum Cnidiae deae nitorem J". ${ }^{19} \mathrm{El}$ Ariosto, canto X: "La damigella non passava ancora / quatordici anni et era bella e fresca / come rosa che spunti all'ora allegra / fuor della buccia e col sol novo cresca" ${ }^{20}$ El Tasso, canto XVI de su Hierusalem, alude mucho al pensamiento de nuestro poeta: "Deh, mira — egli cantó- spuntar la rosa / del verde suo modesta e verginella / che mezzo aperta ancora et mezzo ascosa / quanto si mostra men, tanto è più bella". ${ }^{21} \mathrm{Y}$ el Marino en aquella dulcísima canción de la rosa: "Mira, mira, poi questa / ch'aperto apenna ha l'uscio, / verginella modesta / trar non osi la testa, / pur de purpurei lampi / quasi stella terrena illustra i campi". ${ }^{22}$ Los cuales imitó Bartolomé de Argensola en una canción: "Las rosas, cuando de ellas más compuesta / su abril adorna la nativa espina, / que una sus hojas en belleza inculta / confiada dilata, otra se inclina / dentro en sí misma, tímida y modesta / con virginal modestia medio oculta”. ${ }^{23}$

Podría afirmarse que en este sucinto comentario Díaz de Rivas traza el recorrido de una imagen floral desde la poesía latina de época imperial tardía hasta la lírica barroca europea, haciendo algunas calas esenciales en la pervivencia del motivo (Ponce Cárdenas 2021). Nuevamente conviene notar cómo el erudito cordobés no solo atiende a posibles modelos líricos recientes (Marino, Argensola) sino que se fija también en la escritura nupcial tardo-antigua y humanística (el Epithalamium Honorii et Mariae de Claudiano, los Hendecasyllaborum Libri Duo de Pontano) y en la tradición épica in volgare (Ariosto, Tasso). De entre los distintos escritores que selecciona, parece poner especial énfasis en dos autores y dos géneros: el Claudiano epitalámico (“Quizá es imitación de Claudiano”) y el Tasso épico ("el Tasso alude mucho al pensamiento de nuestro poeta”).

atreve a recibir los rayos solares en sus tiernos pétalos'. Puede leerse otra traducción castellana moderna de Castillo Bejarano (p. 251).

19. Pontano, carmen XIII (Ad Ariadnam uxorem) de Baiae siue Hendecasyllaborum Libri Duo, vv. 11-26 (ed. R. G. Dennis, p. 38).

20. Ariosto, Orlando furioso, canto X, octava 11, vv. 1-4 (ed. L. Caretti, I, p. 227). En la traducción quinientista de Jerónimo de Urrea rezan así estos endecasílabos: "Sabed que no pasaba la señora / de catorce años, tierna, fresca y bella / como rosa que apunta así a la hora / y con el nuevo sol crece y destella” (ed. F. J. Alcántara, p. 125).

21. Torquato Tasso, Gerusalemme liberata, canto XVI, octava 14, vv. 1-4 (ed. L. Caretti, p. 357).

22. Marino (Rime, pp. 60-61). 'Mira, mira después esta, que apenas se ha entreabierto, modesta y pequeña virgen, no osa alzar la cabeza y, sin embargo, con resplandores purpúreos, como una estrella terrenal, ilumina los campos'

23. Bartolomé Leonardo de Argensola, Canción a la primavera, vv. 43-48 (Rimas, ed. J. M. Blecua, I, pp. 12-13). 
Atendiendo a algunos rasgos específicos de la misma, no interesa aquí tanto la visión (más o menos cristalizada) de la comparación general de la belleza femenina con la reina de las flores, sino cómo la figura poética se asigna a un tipo específico dentro de un conjunto amplio y variado. Dentro del tenor general, el símil de Claudiano se aplicaba a dos figuras femeninas de edad dispar: Serena y María, madre e hija. Tal circunstancia posibilita la distinción en dos clases determinadas y la constitución de una suerte de escala, pues establece un contraste sutil entre la hermosura en plena sazón (Serena) y la belleza que despunta (María), la mujer madura como una rosa que muestra ya sus pétalos abiertos y la doncella a punto de desposarse, como una flor que esconde aún sus pétalos en el botón vegetal ("latet nodo"). Por otro lado, dentro del conjunto de parangones esgrimido por Díaz de Rivas, en esa línea que subraya la temprana eclosión de la hermosura de la joven alabada, es interesante apreciar cómo Ariosto insistía en el detalle de la tierna edad: "La dama no excedía los catorce años".

De los modelos propuestos por Díaz de Rivas, el único que consideró atendible Salcedo Coronel algunos años más tarde en su edición de las Soledades comentadas (1636) fue Torquato Tasso:

Esta comparación la tomó nuestro poeta de Torquato Tasso en el canto XVI de su Jerusalén: "Deh, mira (egli cantò) spuntar la rosa / dal verde suo modesta e verginella / che mezzo aperta ancora, e mezzo ascosa / quanto si mostra men tanto è piú bella". Yo, imitándole en mi Anaxarte dije: "Mira la rosa, que del seno rudo / libra modesta su beldad lozana, / hermosa más cuanto en el verde nudo / menos descubre la purpúrea grana" (f. 153v).

Salcedo no solo recoge en su comentario el mismo símil de la Gerusalemme liberata aducido años atrás por su predecesor, sino que asevera de forma taxativa que Góngora "tomó" la "comparación” de la admirada epopeya tassesca. Los cuatro elementos coincidentes que pudo percibir son: "bella" / "beldad", "verde" / "verde", "verginella" / "virgen", "mezzo ascosa" / "se esconde". De hecho, para abonar su opinión recurrirá a su propia experiencia como creador, indicando que él mismo había tratado de emular el parangón floral en el epilio que había consagrado a la trágica historia de Ifis y Anaxárete (García Jiménez 2013: 248). ${ }^{24}$ Efectivamente, los calcos no dejan lugar a duda sobre la derivación. Salcedo calca la exhortación inicial ("Mira" > "Mira"), el sentido ejemplar que se pretende dar a la flor (en la línea del carpe diem horaciano o el collige, uirgo, rosas de Ausonio) y la estructura comparativa de aparente signo paradójico que sirve de cierre ingenioso ("quanto si mostra men tanto è piú bella" > "hermosa más cuanto menos descubre"). Por otro lado, podría afirmarse que la fórmula de los versos italianos referida a la eclosión de la flor ("spuntar la rosa [...] modesta") pudo someterse a una variación libre en el giro "libra modesta su beldad".

24. Se trata de los versos 289-292 del poema mítico-narrativo. 
Tras la exhaustiva monografía que Mercedes Blanco consagró hace poco a la materia, no es necesario insistir en la idea de que Góngora fue un lector atento y sensible de la Gerusalemme liberata, alguno de cuyos rasgos trató de emular en las Soledades (Blanco 2012). Sin embargo, al rastrear el posible modelo literario del símil de la rosa creo que no conviene centrarse tanto en la imagen de la flor que Tasso adscribe al canto de un ruiseñor y ensalza en un pasaje del jardín de Armida, tal como apuntaran Díaz de Rivas y Salcedo Coronel. De hecho, si nos fijamos en varios detalles relevantes, la rosa aparecía allí como cifra de lo efímero o signo admonitorio, al modo de un exemplum que antecede a la llamada voluptuosa, no bajo la forma de un símil. En verdad resulta necesario atender a otra posible fuente tassesca, cuya modulación resulta bastante más cercana a la troquelación gongorina: se trata de una comparación laudatoria que pudo haber pasado desapercibida a los comentaristas antiguos.

\section{Un hipotexto oculto: la rosa virginal entre Tasso y Góngora}

Como intentará mostrarse en los siguientes párrafos, el modelo que tuvo presente Góngora no habría que buscarlo en el sublime estilo de la Gerusalemme, sino entre los ejemplos de "vaghezza" y "fiorito ornamento" del estilo "venusto" o lírico (Tasso, Prose, ed. Ettore Mazzali, p. 657). En efecto, la vasta colección de las Rime ofrecía infinidad de teselas caracterizadas por la elegancia en el concepto y el refinamiento en la forma. De hecho, la admiración inequívoca que el escritor cordobés sentía por los sonetos, canciones y madrigales de Torquato Tasso se trasluce de las numerosas imitaciones de los versos del ferrarés que acometió a lo largo de su trayectoria, tanto en su juventud como en su madurez. Por ejemplo, los pliegues melancólicos y sensuales de la canción ; Qué de invidiosos montes levantados! no podrían entenderse cabalmente sin la identificación del hipotexto de la canzone XLI de las juveniles Rime per Lucrezia Bendidio (Rime eteree, ed. R. Pestarino, pp. 272-292). ${ }^{25}$ En el campo de los sonetos, desde las glosas de Salcedo Coronel, numerosos estudios han aclarado cómo Góngora trató de emular diferentes composiciones de las Rime d'occasione o d'encomio tassescas (Alonso 1982: 352-361, 370-372, 376-379, 381-382, 385-386): el soneto "Poi che scarso m'è Apollo e che non spira" sirvió de modelo para la composición del elogio a Luis Gaytán de Ayala ("Ya que con más regalo el campo mira"); la alabanza del "labro di sotto della signora Leonora Sanvitale, il quale è alquanto ritondetto e si sporge fuori con mirabil grazia" que Tasso trazara en el soneto "Quel labbro che le rose han colorito" se refleja en la sensual composición que principia "La dulce boca que a gustar convida". Dentro del grupo de las rime amorose, la ensońación erótica de "Varia imaginación que en

25. Para un estudio en profundidad de dicho hipotexto, permítase remitir a Ponce Cárdenas 2006. 
mil intentos" dialoga con la pieza tassesca "Pensier, che mentre di formarmi tenti"; los recelos ante el mar de amor que el melancólico ferrarés modelaba en "Ben veggio avvinta al lido ornata nave" sustentan la redacción del soneto "Aunque a rocas de fe ligada vea" (Góngora, Sonetos, ed. J. Matas caballero, pp. 355$360,404-411,420-424,471-475)$... Del rico venero de las rimas de Torquato Tasso tomó Góngora materiales a manos llenas y, según las prácticas del tiempo, trató de borrar algunas huellas del ejercicio imitativo introduciendo modificaciones en el texto original según convenía a sus intereses.

Para entender la matriz originaria de la que surgió el símil de la rosa engastado en la Soledad primera, habría que atender quizá al arranque de un exquisito soneto cortesano de Torquato Taso. La pieza lleva por rúbrica Loda la bellezza della signora Lucrezia d'Este, duchessa d'Urbino, la quale non scema perché cresca l'età. ('Alaba la belleza de la señora Lucrezia d'Este, duquesa consorte de Urbino, cuya hermosura no decrece porque aumente su edad'):

\author{
Negli anni acerbi tuoi purpurea rosa \\ sembravi tu, ch'ai rai tepidi, a l'ôra \\ non apre'l sen, ma nel suo verde ancora \\ verginella s'asconde e vergognosa; \\ o piú tosto parei, ché mortal cosa \\ non s'assomiglia a te, celeste Aurora \\ che le campagne imperla e i monti indora \\ lucida in ciel sereno e rugiadosa. \\ Or la men verde età nulla a te toglie; \\ né te, benché negletta, in manto adorno \\ giovinetta beltà vince o pareggia. \\ Cosí piú vago èl fior poi che le foglie \\ spiega odorate, e'l sol nel mezzo giorno \\ via piú che nel mattin luce e fiammeggia. ${ }^{26}$
}

(Tasso, Rime, ed. B. Basile, I, p. 570)

Como indicaba uno de los mayores especialistas en las rime tassianas, la redacción original del soneto se puede datar bien hacia los primeros meses de 1570 , bien en torno a 1575. La primera fecha podría conectarse al momento

26. 'En tus años inmaduros purpúrea rosa / parecías, que a los tibios rayos, al aura / no abría el seno, sino en su verde botón / pequeña y virgen se esconde vergonzosa. / O más bien serías igual, pues una cosa mortal / no se parece a ti, a la celeste Aurora / que los campos rocía y los montes dora, / luciente en el cielo sereno y aljofarada. / Ahora la edad menos verde nada te arrebata / ni a ti, incluso sin adornos, en ornado manto / una joven beldad te vence o te iguala. / Así más atractiva es la flor cuando los pétalos / despliega perfumados y el sol al mediodía / mucho más que en la mañana luce y calienta'. 
capital de las nupcias de Lucrezia d'Este con Francesco Maria della Rovere, el heredero del ducado de Urbino (18-II-1570). La novia contaba entonces con una edad bastante avanzada para tratarse de un primer matrimonio (treinta y cinco años), en tanto que su flamante esposo era considerablemente más joven que ella (pues acababa de cumplir veintiuno). La galantería de la pieza laudatoria podría, pues, girar en torno a la idea de que una rosa en el ápice de su hermosura es más bella que la misma flor cuando empieza a despuntar, al igual que la aristócrata ferraresa, cuya beldad madura es superior a la hermosura que lucía en la ya lejana adolescencia. La segunda fecha posible de redacción del soneto se vincularía a la estancia de Torquato Tasso en el ducado de Urbino, en 1575, cuando gozó nuevamente del mecenazgo de la aristocrática dama, que pasaba entonces por un período de convalecencia. Sea como fuere, los delicados versos encomiásticos se cuentan por derecho propio "fra le più riuscite celebrazioni tassiane della bellezza femminile, ma d'una bellezza che è tutt'uno con la stagione e il paesaggio della memoria poetica, con la suggestione profonda dello scoprirsi in assoluta armonia con l'universo. Dalle dolci e tenere parvenze della rosa celata a quelle ariose e fervide del fiore aperto nel suo pieno rigoglio". Con toda justicia se ha sostenido que la pieza de Tasso constituye "un esempio ragguardevole" de escritura lírica "quanto mai sottile e raffinata" (Caretti 1950: 211).

Hasta donde se me alcanza, la crítica tassiana se ha ocupado con sumo interés de los diferentes estadios redaccionales y del conjunto de las variantes de esta pieza (Caretti 1950, Montagnani 1985), mas no ha insistido demasiado en el posible magisterio de algún modelo clásico latente. Cabría estimar, sin embargo, que bajo la superficie de aquella alabanza áulica subyacía otro refinado encomio de signo imperial o tardo-antiguo. Con las debidas cautelas, quizá podría postularse un influjo directo del parangón con el que Claudiano elogió la belleza madura de Serena y la beldad juvenil de María en el Epithalamium de nuptiis Honorii et Mariae (Visentini 2018: 118). La comparación doble de madre e hija con dos rosas de Paestum en un momento de eclosión diverso se aplicaría ahora, de forma bastante original, a una sola figura femenina (la aristocrática Lucrezia d'Este) en dos momentos diferentes de su vida. ${ }^{27}$

27. El epitalamio que Tasso compuso en 1578 en honor de las bodas de Alfonsino d'Este il Giovane y su pariente Marfisa d'Este incorporaba varios ecos directos del Fescenninum IV de Claudiano. Este detalle prueba sin margen de dudas que el poeta de Ferrara tenía bastante familiaridad con los poemas nupciales del autor tardo-antiguo. Dicha cuestión invita a sospechar que varios años antes, Tasso podría manejar ya los mismos modelos epitalámicos. Podría plantearse igualmente como hipótesis que la fecha de redacción del soneto podría ser 1570, estableciendo una relación directa con el momento de las bodas de la dama ferraresa con el heredero del ducado de Urbino. En dicho contexto cobraría pleno sentido que Tasso hubiera consultado con provecho los carmina nuptialia de Claudiano para encontrar alguna fuente de inspiración. Por otro lado, refuerza la tesis del hipotexto claudianeo otro particular interesante. Entre el segundo cuarteto y los versos finales del segundo terceto, Tasso introducía un segundo símil para ponderar que la belleza madura supera a la hermosura juvenil: el Sol al mediodía fulge con más esplendor que la Aurora 
A la luz de estos nuevos datos, en la memoria poética de Góngora podrían, pues, convivir tanto el dechado claudianeo como la imitación tassesca del mismo. De hecho, en el marco epitalámico de la Soledad primera afloran otros ejemplos de rescritura aplicados al hipotexto del Epithalamium de nuptiis Honorii et Mariae, tal como advirtiera tempranamente Pedro Díaz de Rivas (Góngora, Soledades, ed. R. Jammes, pp. 358-361). Sea como fuere, el genial racionero debió de sentirse especialmente atraído por la acuñación floral que Tasso modelaba en el primer cuarteto, cuyos versos va a someter a un intenso ejercicio de rescritura.

Si se disponen ambas comparaciones una detrás de otra, puede evidenciarse en negrita el conjunto de paralelos o elementos coincidentes, que deberán comentarse con posterioridad.

Negli anni acerbi tuoi purpurea rosa

sembravi tu, ch'ai rai tepidi, a l'ôra

non apre'l sen, ma nel suo verde ancora

verginella s'asconde e vergognosa;

la que en sí bella se esconde

con ceño dulce y con silencio afable

beldad parlera, gracia muda ostenta,

cual del rizado verde botón, donde

abrevia su hermosura virgen rosa

las cisuras cairela

un color que la púrpura que cela

por brújula concede vergonzosa

De los siete elementos que Góngora extrae del parangón de Torquato Tasso tan solo tres van a permanecer intactos. Sirven estos así de firme guía en la identificación del hipotexto: "rosa" > "rosa", "s’asconde" > "se esconde", "vergognosa" $>$ "vergonzosa". En el ejercicio de rescritura se mantienen, a modo de ancla, las palabras-rima del modelo: "rosa", "vergonzosa". ${ }^{28}$ Otro concepto central que per-

en las primeras luces del alba. Podría tratarse de una acertada variación sobre otra comparación empleada por el vate alejandrino en el Epithalamium de nuptiis Honorii et Mariae (v. 243). El segundo parangón claudianeo se sustentaba en la otra gran luminaria celeste con el fin de contrastar la beldad madura de Serena y el juvenil encanto de María: "Haec modo crescenti, plenae par altera lunae" ('una es igual que la luna creciente, la otra como la luna llena').

28. El uso del mismo rimema (-OSA) y de idénticas palabras-rima (rosa-vergognosa) se localiza en otras muestras más extensas del símil en la obra tassiana. Pienso en la comparación inserta en la canción-diálogo Arezia ninfa, donde el apasionado Tirinto cuenta sus penas de amor a la compasiva Arezia (vv. 73-89), que trata de animarlo valiéndose del parangón floral: "che, qual tenera rosa / a la rugiada, a l'ôra / de la nascente Aurora / non apre vergognosa / il suo vermiglio ed odorato seno: / ma, poi che più vicino il caldo sente / de'l gran pianeta ardente, / apre languendo le purpuree spoglie / e'l bel raggio de'l sole in grembo accoglie: / così la verginella / ai pianti ed ai sospiri / di novello amator che lunge miri, / chiude il ritroso petto; / ma, poi che s'avvicina il vivo ardore / d'un amoroso aspetto, / languendo apre la via per gli occhi al core / e nel vergineo sen riceve Amore" (Tasso, Teatro, ed. A. Solerti, pp. 412-413). 
manece inalterado es la acción de ocultamiento: "s'asconde" > "se esconde". De hecho, la elección de este verbo remite a su vez al modelo tardo-antiguo de Claudiano, que había fijado ya la misma idea: "latet nodo" ('se esconde en el botón' / 'se esconde en el nudo vegetal' / 'se esconde en el capullo'). ${ }^{29}$ La huella de la iunctura claudianea se identifica en la troquelación tassesca "nel suo verde s'asconde", que a su vez genera la acuñación gongorina "en sí bella se esconde", que reproduce - alterando la adjetivación - la andadura rítmica del modelo italiano. ${ }^{30}$

Atendiendo a este tipo de reflexiones, conviene recalcar que durante todo el Siglo de Oro la praxis de la imitación poética es en esencia transformativa, puesto que invita a los autores a recoger lo más granado de los poetas que les han precedido y a reelaborarlo con otro aire, dotando así de un sello personal a los materiales seleccionados. El ejercicio imitativo había de modularse, pues, conforme a un proceso de asimilación y cambio. ${ }^{31}$ Como era común en la época, el fragmento imitado se modificaba conforme a cuatro procedimientos esenciales: adición, detracción, inversión e inmutación o, en la terminología de Quintiliano, adiectio, detractio, transmutatio e inmutatio. Según definiera tales operaciones Baltasar de Céspedes en el diálogo El humanista, la adición "es cuando para nuestro propósito hemos de añadir algo a lo que el autor escribió"; la detracción "es cuando quitamos del lugar que queremos imitar alguna cosa que no hace a nuestro propósito [y ha de] tener cuenta que no parezca que se ha destrozado y cortado aquello con fealdad, sino que queda cabal nuestra composición"; la inversión "es cuando las palabras del autor se trastuecan y mudan de lugar para que no parezcan las mismas"; la inmutación "es

29. Pueden evocarse aquí algunas de las traducciones de la iunctura "latet nodo" a diferentes lenguas modernas, como la de Jean-Louis Charlet ("se cache en bouton"), la de Edoardo Bianchini ("è chiusa in boccio") o la de Miguel Castillo Bejarano ("está oculta en su capullo").

30. Bajo el signo de una compleja cadena imitativa, la conexión "Claudiano > Tasso > Góngora" se percibiría igualmente en otro símil de la Soledad primera referido a la novia aldeana, pues se la compara posteriormente con el ave Fénix. Sobre esa nueva muestra de imitatio arqueológica o imitación por estratos, permítase remitir a Ponce Cárdenas (2014b).

31. La necesidad de introducir modificaciones de distinto tipo para enmascarar el ejercicio imitativo no afecta solo al plano de la lexis. Si se atiende, por ejemplo, al terreno de la inuentio, una y otra vez se percibe entre los poetas y eruditos del tiempo el eco de un celebérrimo fragmento de la Epistula ad Pisones de Horacio (v. 128): "difficile est proprie communia dicere" ("Es difícil decir como algo propio lo que es de todos': Horacio, Arte poética, trad. y ed. Juan Antonio González Iglesias, pp. 66-67). Así Johannes Sturm afirmaba a zaga del venusino: "oportet nos imitatione ex alieno facere proprium" ('conviene que hagamos propio lo ajeno a través de la imitación') (Sturm, De imitatione oratoria, s.f.). En los Discorsi dell'arte poetica, Torquato Tasso recalcaba que por muy trillado que sea un argumento, los excelsos creadores "variamente tessendolo, di commune proprio e di vecchio novo il facevano" ('tejiéndolo con variedad, lo hacían de algo que era común, propio y de viejo, nuevo': (Tasso, Prose, ed. Ettore Mazzali, p. 352). En ámbito propiamente gongorino, en las Anotaciones al Polifemo, Pedro Díaz de Rivas apuntaba esa misma idea a zaga de Horacio: "Licencia es frecuentísima en los poetas el variar las fábulas [...] y es cierto género de gala el hacer esto disponiéndolo con nuevos colores de invención, con que la fábula común se hace como propia” (BNE, Ms. 3906, f. 127r). Sobre la teoría y la praxis imitativa en España e Italia, pueden verse dos recientes monografías: Ponce Cárdenas 2016 y Carminati 2020. 
cuando en lugar de un vocablo se pone otro, o para variar la oración, o para mudar la significación de nuestro propósito" (ed. M. Comellas, pp. 32-33).

Dentro del campo de la adición amplificativa, en el símil de la Soledad primera se ańaden otras teselas que no pertenecen al "mosaico" original italiano. Se trata del contenido de los versos 725-726: "con ceńo dulce y con silencio afable / beldad parlera, gracia muda ostenta". El apartado de la detracción resulta igualmente fácil de identificar, ya que Góngora elimina la referencia temporal a la edad de la figura femenina ("Negli anni acerbi tuoi" 'En tus ańos inmaduros' / 'En tus verdes años') así como todo lo referido a los rayos del sol y la templada brisa ("ai rai tepidi, a l'ôra non apre il sen" 'a los templados rayos, al aura no abre el seno').

Bajo el signo del tercer procedimiento, la transmutatio o inversión de posiciones' dentro del pasaje, la praxis imitativa lleva a Góngora a enmascarar el ejercicio de rescritura mediante una notable alteración en el orden de presentación de los elementos del modelo:

$\begin{array}{ll}\text { Tasso } & \text { Góngora } \\ & \\ \text { 1. purpurea } & \text { 6. en sí bella se esconde } \\ \text { 2. rosa } & \text { 3. cual } \\ \text { 3. sembravi } & \text { 4. verde botón } \\ \text { 4. nel suo verde } & \text { 5. virgen } \\ \text { 5. verginella } & \text { 2. rosa } \\ \text { 6. s'asconde } & \text { 1. púrpura } \\ \text { 7. vergognosa } & \text { 7. vergonzosa }\end{array}$

La dispositio de los pequeños constituyentes del símil arroja así un orden masivamente modificado, en el que tan solo se ha mantenido en la posición original el último elemento: 6-3-4-5-2-1-7.

Finalmente, a través de la inmutatio, Góngora "en lugar de un vocablo" va a colocar algún que "otro" término impulsado por la voluntad de "mudar la significación" conforme a sus designios personales" o con el "propósito" de "variar la oración". Dentro de dicha modalidad transformativa figura, por ejemplo, la modificación de algunas categorías de palabras: el calificativo que proporciona la nota de intenso colorido en el hipotexto se convierte en un sustantivo análogo ("purpurea" > "púrpura"). En el terreno de la modificación verbal se aprecia asimismo cómo el epíteto referido a la flor en Tasso viene modulado por el uso del diminutivo, tan común por otra parte en la poesía italiana de la época ("verginella"), mientras que Góngora prescinde de dicha nota afectiva, quizá en exceso amanerada o sentimental ("virgen"). Igualmente destacable es el cambio en el nexo que sirve para introducir el símil: el hipotexto italiano recurre a una acuñación verbal cristalizada en las comparaciones de igualdad o semejanza ("sembravi" / 'parecías') en tanto que Góngora recurre a un nexo de sabor levemente latino (“cual”), que evoca lejanamente el clásico qualis. 
La inmutación que promovía los distintos cambios en el plano léxico no sólo se circunscribe a los tres ejemplos citados sino que puede identificarse también en la llamativa incorporación de un pequeño caudal de términos interrelacionados que van a componer una curiosa isotopía. En efecto, la incorporación de varios vocablos relacionados con el orbe de los tejidos resulta tan novedosa y llamativa que merece examinarse en un apartado específico. ${ }^{32}$

\section{Relieves del parlare ardito: entre la glosa y la reprobación}

Al poner el foco en el plano de la elocutio referida al símil de la rosa, no escapó a la percepción de algunos receptores del siglo XviI la innovadora selección léxica que Góngora había aplicado a la misma. Ya desde el orbe de la invectiva, ya desde la esfera de la anotación minuciosa, contamos hoy con el testimonio de cuatro lecturas que arrojan desde ángulos afines bastante luz sobre la llamativa opción gongorina. A lo largo de las siguientes líneas nos servirán, pues, de guía para la reflexión los escritos de Manuel Serrano de Paz, Juan de Jáuregui, Pedro Díaz de Rivas y Francisco de Quevedo.

Al compararlas con las glosas -impresas o manuscritas- de otros comentaristas, puede percibirse cómo las anotaciones que ofrecía Manuel Serrano de Paz presentan en este punto mayor interés, precisamente por la atención que dedicaba al léxico. El erudito ovetense incorporaba aquí tres notas referidas al participio "rizado", a la frase "las cisuras cairela" y al modismo "por brújula". En primer lugar, así reflexionaba sobre el primer epíteto del sintagma "rizado verde botón" (f. 497v): "Llámale el Poeta rizado por causa de aquel vello y espinas menudicas que le hacen crespo y áspero, que esto es rizado". Con mayor detenimiento aún se ocupó de aclarar el significado de la frase "las cisuras cairela" (f. 498r):

El Poeta las llama cisuras porque en ellas se divide el botón, como en jirones suyos, y así las llaman algunos latinos lacinia. A éstas dice cairela el color de la rosa. Llámase cairel, como es notorio, una trenza, guarnición, pasamano o bordadura con que se guarnecen los remates y bordes de cualquier cosa de lana o seda y suelen ir labrando el cairel con la aguja sobre la misma estofa que se guarnece. Así cairela el color de la rosa sus cisuras porque se muestra entre una y otra, como nacido o pegado a sus extremos y así los guarnece.

Parece evidente que si el comentarista se tomó la molestia de aclarar el sentido del sustantivo "cisuras" y el verbo "cairelar" fue porque pretendía mostrar la propiedad de la metáfora, desarrollando la imagen. ${ }^{33}$ La dificultad de tales

32. Sobre la "especificidad del lenguaje gongorino", véase la importante reflexión de Carreira (2021: 19-40).

33. Con generosidad suma, me apunta Mercedes Blanco la siguiente precisión: Manuel Serrano 
voces obedecía a razones distintas: la primera era un préstamo directo del latín ("scissura"), la segunda introducía una referencia un campo léxico tan inusitado como el de las labores de aguja ("cairela").

Siguiendo el hilo conductor que proporciona Serrano de Paz quizá sea lícito ahondar en ese último aspecto, ya que la evocación plástica del capullo de la flor, que a través de algunas leves líneas o sutiles aberturas deja entrever los nacientes pétalos de un rojo encendido, podría erigirse conceptualmente sobre un novedoso haz de isotopía relacionado con el campo semántico de la costura y el tejido. En verdad la configuración del eje isotópico podría ramificarse a través de cuatro términos: "rizado", "botón", "cisuras", "cairela". Más allá de lo apuntado por el comentarista, sospechamos que la selección del participio del verbo "rizar" no fue del todo inocente, ya que si bien el vocablo remite en su acepción más extendida a la acción de "formar en el pelo artificialmente anillos o sortijas, bucles, tirabuzones", también solía emplearse con un matiz técnico, como el de "hacer en la tela dobleces menudos que forman diversas figuras" (RAE) y era bastante común para designar algunos tipos de tejidos, como el "brocado rizado" (con el que se hacían las capas pluviales, planetas y tunicelas) o la "felpa rizada". Por otro lado, la voz "botón" designa sin ambages la "flor cerrada y cubierta de las hojas que unidas la defienden, hasta que se abre y extiende", pero también puede referirse a la "labor a modo de anillo formado por bolas o medias bolas con que se adornan balaustres, llaves y otras piezas de piedra, metal u otra materia" (RAE). El sustantivo "cisuras" (del latín scissura) se refiere a la "rotura o abertura sutil que se hace en cualquier cosa". Por último, el verbo "cairelar" acota con un grado llamativo de precisión otro tipo de actividad relacionado con el ámbito de la pasamanería y los ornamentos del vestido, puesto que

[El cairel es] un entretejido que se echa en las extremidades de las guarniciones, a modo de pasamanillo, salvo que el pasamano se teje en el telar y el cairel en la misma ropa dividiendo la aguja lo que había de hacer la trama en la lanzadera y los hilos de los lizos traen los dedos de las manos trocándose [...]. Cairelar [es] echar caireles. Cairelado, la obra que los lleva (Covarrubias, Tesoro de la lengua, pp. 262-263).

De resultar plausible la hipótesis sobre el haz de isotopía formado por los cuatro términos ("rizado" / "botón" / "cisuras" / "cairela") en el símil imitado del soneto tassesco se hallaría una novedad curiosa, ya que a través de esas voces

de Paz afirma que "las cisuras son los 'jirones', esto es, las partes del capullo (los sépalos), cuando son en realidad los intersticios entre ellos por donde asoman los pétalos (con su color púrpura), como si los sépalos fueran el resultado de un corte. De ese modo, la rosa no solo se describe con valores plásticos sino que se exalta casi como un objeto artificial, una diminuta obra de arte o un exquisito objeto de elaborada artesanía”. 
dilógicas se encapsula un recóndito juego de ingenio. La copia uerborum sirve así para ostentar agudeza, dado que a través de la misma el autor hace gala de un virtuosismo singular en el dominio de la semántica. ${ }^{34}$

Otro elemento léxico que sirve de sello personal gongorino a esta rescritura es la utilización de un giro tan llamativo como "por brújula concede", una expresión ausente del modelo tassesco y que, por tanto, cabe computarla como ejemplo de inmutatio en el proceso imitativo. No estará de más recordar cómo el uso de la voz "brújula" en el castellano áureo remitía ante todo al ámbito de la caza, pues designa — como atestiguaba Covarrubias en 1611- "el agujerito de la puntería de la escopeta" (Covarrubias, Tesoro de la lengua, p. 239). El mismo lexicógrafo aclaraba que "es menester mucho tiento y flema para encarar con él y lo mismo tienen algunos instrumentos matemáticos, como el astrolabio, la ballestilla y el báculo astronómico y otros" (ibidem). Ahora bien, desde un segundo plano, se vincula expresivamente al ámbito del juego de cartas, ya que "los jugadores de naipes - que muy despacio van descubriendo las cartas y por sola la raya antes que pinte el naipe discurre la que puede ser- dicen que "miran por brújula" y que "brujulean" (ibidem).

Lejos de escandalizarse o considerar impertinente la utilización del modismo "por brújula", Manuel Serrano de Paz disertaba con gran tino sobre el acierto que conlleva el peculiar uso de este giro en otro párrafo de sus comentarios:

Llámase brújula la mira o visera del arcabuz o del astrolabio, por donde se guía el rayo visual al blanco para tirar derecho y no errar; y como por la brújula se da a los ojos muy corto espacio, que es aquel solo donde se hace el tiro o por un pequeño agujero se mira una estrella entera. Así cuando la rosa apunta con su color por entre las cisuras del botón, solamente muestra un punto de la púrpura que tiene y en este representa toda su hermosura y así parece que la da por brújula a los ojos, que por las cisuras hacen puntería a su hermosura (Serrano de Paz, Comentarios a las Soledades, f. 498r-v).

La incorporación de este uso léxico podría suponer una ligera sacudida estética para los lectores más atentos y receptivos, que apreciarían cómo el símil se 'actualizaba' y se 'transformaba' gracias al empleo de una materia verbal inusitada.

Con un término inesperado - entreverado de resonancias cinegéticas y lúdicas a un tiempo- el ingenioso Góngora daba forma a la sorpresa y delei-

34. Pocos años antes que Góngora, ya había hecho uso del vocabulario textil aplicado a una flor Giovan Vincenzo Imperiale en Lo stato rustico (parte XV, vv. 981-986): “Qui tra'l morello e tra'l vermiglio imbianca / al capo verdeggiante il crin lascivo / ligure gelsomino e verginello: / che, con sue dita candide e minute, / del verno ancor sul gelido telaro / fila odor, pompa ordisce e grazia tesse" (Imperiale, impr. G. Pavoni, en 1611, pp. 728-729). No he tenido acceso a un ejemplar de la edición príncipe de 1607 , por ello he tomado como referencia el texto de la segunda impresión del poema. Ahora puede consultarse también la magnífica edición moderna (ed. O. Besomi, A. López-Bernasocchi y G. Sopranzi, I, p. 532). 
te que el peregrino experimenta al observar por vez primera a la bella novia aldeana. Ahora bien, haciendo algo de memoria, no fue esta la única ocasión en la que el poeta andaluz se valió de este vocablo en un contexto semejante. De hecho, debía de resultarle especialmente feliz el hallazgo verbal, puesto que lo insertó en diferentes poemas que comparten un mismo rasgo: en todos ellos se esbozan escenas que aluden a cierta contemplación o regodeo sensual. Entre 1582 y 1612 pueden identificarse hasta cuatro ocurrencias significativas del término. Siguiendo el orden cronológico, la primera aparece en la canción juvenil Corcilla temerosa (vv. 18-22): "a luchar baja un poco con la falda, / donde no sin decoro / — por brújula, aunque breve - / muestra la blanca nieve / entre los lazos del coturno de oro" (Góngora, Canciones y otros poemas en arte mayor, ed. J. M. Micó, p. 55). El giro "por brújula" nuevamente hace acto de presencia en un romance datado en 1590: Dejad los libros ahora (Góngora, Romances, ed. A. Carreira, I, pp. 515-517). El pasaje que nos interesa reza así (vv. 41-52): "Lo demás, letrado amigo, / que yo os pudiera decir, / por mi fe que me ha rogado / que lo calle, el faldellín; / aunque, por brújula, quiero, / si estamos solos aquí, / como a la sota de bastos, / descubriros el botin: / cinco puntos calza, estrechos, / y esto, señor, baste; al fin, / si hay serafines trigueños, / la moza es un serafín". En otro famoso romance, fechado en 1603, En los pinares del Júcar, daba cabida a una serie de elementos similares, entre los cuartetes que describen el encanto oculto de las serranas que danzan (vv. 2730): "El pie, cuando lo permite / la brújula de la falda, / lazos calza y mirar deja / pedazos de nieve y nácar” (Góngora, Romances, ed. A. Carreira, II, p. 113). Por último, cabría recordar la utilización del mismo vocablo en la octava XXXVII del Polifemo, precisamente en la escena en la que Acis con los ojos entornados contempla con arrobo cómo Galatea se va aproximando a su persona, pues la inocente nereida le creía dormido: "Acis aun más de aquello que dispensa / la brújula del sueño vigilante, / alterada la ninfa esté o suspensa, / Argos es siempre atento a su semblante" (Góngora, Fábula de Polifemo y Galatea, ed. J. Ponce Cárdenas, p. 173).

Una canción, dos romances y el epilio proporcionan una gavilla de lugares paralelos que prueban cómo en la estimativa gongorina el giro podía usarse en una canción petrarquista, en un romance jocoserio, en una composición octosilábica de sabor rústico y en un relato mitológico en octavas. El giro no se asociaría del todo ni a un estilo alto, ni a un estilo bajo, sino que podía moldearse a voluntad y adaptarse a diferentes fines. En suma, si se observa con atención un conjunto de escenas vinculadas temáticamente por la observación de la hermosura femenina (contemplada a veces mediante alguna astucia o estratagema o, simplemente, valiéndose de una ocasión favorecedora) el uso reiterado de la voz "brújula" o el modismo "por brújula" nos sitúa ante una suerte de cliché o rasgo estilístico. Gracias a tal detalle podríamos advertir cómo, a veces, Góngora no parece sentir gran aversión por la rescritura: cuando encuentra una fórmula o una acuñación verbal que por un motivo u otro le satisface especialmente, el 
poeta cordobés no duda en reutilizarla en varias composiciones, convirtiéndola así en una marca de estilo personal. ${ }^{35}$

Si en la primera recepción de la poesía gongorina los comentaristas áureos ofrecen la cara de la moneda, sin duda, la cruz nos la proporcionan los formidables émulos del poeta. Como integrante de este segundo colectivo, no parece exagerado afirmar que Juan de Jáuregui merece figurar en un lugar de honor entre sus más ingeniosos detractores. Fueron muchos los errores que el Aristarco sevillano achacaba al oscuro poema en su divertido Antídoto contra la pestilente poesía de las Soledades, aunque ahora nos interesa centrarnos únicamente en los reparos que allí planteaba a propósito del léxico y la desigualdad de estilo.

En la lista de vocablos inapropiados que aparecen en el texto gongorino, no sin sorna, el escritor sevillano dispuso algunas palabras y giros bajo la etiqueta despectiva de "domésticos modos", ya que según su refinado criterio tales voces no deberían integrarse en una composición de estilo sublime. El autor del Orfeo también hizo blanco de sus críticas algunos vocablos gongorinos que se excedían, precisamente, por lo opuesto: a causa de su condición de préstamos demasiado obvios del latín. Parece significativo que en ambos listados figuren nada menos que cuatro de los términos más llamativos identificados en el símil de la rosa: entre las palabras demasiado humildes Juan de Jáuregui reprodujo el sustantivo "botón", el verbo "cairelar" y el modismo "por brújula" (Jáuregui, Antídoto contra la pestilente poesía de las Soledades, ed. J. M. Rico García, pp. 53-54); entre los latinismos censurados aparecía — junto a "compulsar", "venatorio", "adolescente" o "formidable" - el sustantivo "cisuras". ${ }^{36}$

En el mismo pasaje de la vitriólica invectiva se resalta otro error de bulto. Jáuregui ataca entonces un rasgo muy personal del estilo gongorino, ya que censura la "ensalada y mezcla tan disonante de estilos, de voces y sentencias", la unión de "lo humilde y vulgar con lo terrible y remoto", la mala costumbre de ir "empa-

35. El término también aparecía en otras poesías gongorinas de signo marcadamente cómico. En el romance de 1597 que principia ¿Quién es aquel caballero? se usa, por ejemplo, para ponderar la maliciosa vista de los gitanos, capaces de identificar el punto débil de sus víctimas y someterlas a robos con astucia: "La Necesidad (que tiene / el ánima de un gentil, / la brújula de un gitano, / la conciencia de un neblí) / en el real de don Sancho / me libraba algún cuatrín” (Góngora, Obras completas, ed. A. Carreira, I, p. 175). Como giro naipesco se incluye igualmente en una expresión figurada de la comedia El doctor Carlino (vv. 293-295): "Muy poco importa que mienta / la brújula de la pinta / a los que han hecho setenta" (Góngora, Teatro completo, ed. L. Dolfi, p. 282). En las décimas de 1606 Musas, si la pluma mía, donde satiriza el espacio de la corte y sus desmanes amorosos, pergeña la estampa de un hipócrita que asiste a una danza en la que gracias a los movimientos airosos de los participantes podría contemplar alguna parte oculta (el pie o el tobillo) de las damas: "El más rígido Catón / brujulea una chacona" (Góngora, Décimas, ed. S. Pezzini, p. 76). En este último caso recurría a la variante verbal: "brujulear".

36. El sustantivo "botón" no aparece en la edición del Antídoto cuidada por José Manuel Rico García, pero sí en la versión del opúsculo que cuidó varias décadas antes Eunice Joiner Gates (Gates 1960: 121). Para las réplicas del abad de Rute a los dardos lanzados por Juan de Jáuregui, es obligada la consulta de la nueva edición del Examen del antídoto (ed. Mancinelli, 2019) 
nando una voz muy ilustre entre dos soeces" (ibidem). Llegado a este punto en la diatriba, no parece baladí que el polemista hispalense se explayara un tanto en la condena del modismo "por brújula", puesto que se toma la molestia de insertar todo un paréntesis con ánimo de escarnio: "esto podía quedarse para el botín de la sota de bastos" (Jáuregui, Antídoto contra la pestilente poesía de las Soledades, ed. J. M. Rico García, p. 53). ${ }^{37}$ Ciertamente, el tiro del polemista no iba del todo descaminado. Si una expresión hecha del tenor de "por brújula" remitía — según el testimonio autorizado del más conocido lexicógrafo de inicios del siglo XVII- a los usos jergales del vocabulario naipesco, no parece muy decoroso su uso en un poema que aspira a convertirse en paradigma del nuevo estilo sublime. ${ }^{38}$

Como acaba de verse, el símil de la rosa que articula Góngora no sólo incluía términos demasiado humildes ("cairela") y giros coloquiales en exceso ("por brújula") sino que además tenía la audacia de combinar esos "domésticos modos" con un vocabulario exquisito y remoto, de signo totalmente opuesto, como el cultismo de signo latinizante "cisura" ${ }^{39}$ De hecho, nunca antes había utilizado Góngora esa palabra referida a un corte limpio, ni posteriormente en los versos que escribió hasta su muerte volvería a emplearla.

El escarnio al que fue sometida la obra de Góngora en el Antídoto contra la pestilente poesía de las Soledades generó poco tiempo después una serie de escritos en respuesta firmados por algunos de sus admiradores más destacados. Entre tales defensas, pueden recordarse ahora los Discursos apologéticos por el estilo del Polifemo y Soledades, donde Pedro Díaz de Rivas respondía a las objeciones planteadas por los enemigos del escritor cordobés. Una de las críticas más extendidas era la de haber introducido "numerosas voces peregrinas" que atentaban contra la pureza del castellano. El apologista en su argumentación tratará de quitarle hierro al asunto, afirmando que no son tantas como sostienen las malas lenguas. Se fija para ello en la obra maestra inacabada y, al tiempo que defiende que el latín puede prestar a nuestro idioma "voces elegantes, sonoras, venustas y modos graciosos valientes", afirma que "en la Primera Soledad solas dedujo estas nueve voces" identificables como latinismos: "semicapro, mentido, pululante, arrogante, delicioso, cisura, triplicado, bipartida" (Díaz de Rivas, Discursos apologéticos por el estilo del Polifemo y Soledades, ff. 81v-82r). ${ }^{40}$

37. El picotazo de Jáuregui incorporaba una alusión nítida al fragmento del romance gongorino Dejad los libros ahora, que se ha citado anteriormente. Por tanto, podría leerse entre líneas otro consejo malicioso o advertencia: reservad esas cosas chuscas para la poesía jocoseria, pues no son de recibo en un poema que quiere elevarse al estilo heroico.

38. Para el léxico naipesco, véase la detalladísima monografía de Étienvre (1990) (sobre Góngora y su pasión por el juego de cartas cabe remitir a las páginas 26-29).

39. El término constituye un ejemplo más de hápax en la obra gongorina. Sobre el hápax legómenon es de obligada consulta un trabajo recogido por Nadine Ly en una monografía magistral (Ly 2020: 274-301).

40. La numeración se corresponde a la incluida a lápiz modernamente en el manuscrito BNE 3726. Por otro lado, en el mismo párrafo Díaz de Rivas ańadía que esas mismas palabras "quizá" 
La rareza del término latinizante cisuras debió de resultar sumamente llamativa a ojos de sus detractores, ya que tampoco escapó al finísimo olfato del otro gran azote del poeta cordobés: Francisco de Quevedo. Quiso hacer irrisión de la misma el genial satírico al incorporarla en el primer terceto de su malévola Receta para hacer Soledades en un día (Quevedo, Obras festivas, ed. P. Jauralde Pou, p. 127):

Quien quisiere ser culto en solo un día,

la jeri (aprenderá) gonza siguiente:

fulgores, arrogar, joven, presiente,

candor, construye, métrica, armonía;

poco, mucho, si no, purpuracía.

Neutralidad, conculca, erige, mente, pulsa, ostenta, librar, adolescente, señas, traslada, pira, frustra, harpía;

cede, impide, cisuras, petulante, palestra, liba, meta, argento, alterna, si bien, disuelve, émulo, canoro.

Use mucho de líquido y de errante, su poco de nocturno y de caverna, anden listos livor, adunco y poro.

En definitiva, los testimonios de Serrano de Paz, Jáuregui, Díaz de Rivas y Quevedo configuran las huellas primigenias de una "lectura activa" que hoy se antoja valiosa en grado sumo, en la medida que da información de primera mano sobre los valores de una época y nos orienta sobre el estado del lenguaje poético en un momento dado. Sus aseveraciones pueden servir, además, para tomarle el pulso a la praxis imitativa gongorina a partir de un ejemplo concreto y reflexionar desde ese ángulo sobre algunas cuestiones estilísticas y las innovaciones introducidas por el cabeza de la nueva poesía.

Por mucho que pudiera sorprender a algunos y generar algún que otro aspaviento, en verdad, al insertar dentro de la imitación de un símil tassesco una serie de palabras y modismos llamativos ("botón", "cisuras", "por brújula”, "cairela"), Góngora no hacía sino seguir alguno de los consejos reiterados en los tratados sobre cómo llevar a cabo el ejercicio imitativo. Una y otra vez insisten los preceptistas en la misma recomendación: conviene ocultar las huellas de la imitatio, no es del todo lícito reproducir palabra por palabra los ele-

las "han usado otros". De hecho, no le faltaba razón en ello, ya que el latinismo cisura aparece también en La Dorotea de Lope de Vega: “¡Ay, Julio, que tengo a Dorotea de suerte en las medulas de los huesos después que adolecí de su contacto, que creo que si me sangrasen de la vena del corazón, saldría como azogue por la cisura" (La Dorotea, ed. E. S. Morby, p. 257). 
mentos del modelo. A ese propósito puede recordarse el testimonio del humanista Bernardino Partenio: "No menos alabaría que se tomara de otros de forma tal que la imitación permaneciera escondida [...]. Me parecería que esto está bien hecho cuando las palabras ajenas y las formas de expresión y las sentencias reciben otro grado, de manera que no llegan a reconocerse como tales. Y esta es la forma de imitar que me satisfaría más allá de toda medida" (Parthenio, Della imitatione poetica, p. 108). ${ }^{41}$

La praxis imitativa que distinguimos en el pasaje gongorino viene modulada también por una suerte de densidad semántica, por una mayor tensión expresiva, ya que se sustenta en términos y conceptos no empleados por el modelo. Las palabras reciben así "otro grado" y las figuras de ornato se refuerzan.

A la luz de tales opciones sería oportuno, quizá, ampliar la reflexión al ámbito del nuevo estilo acuñado por el genial racionero conectándolo con otros intentos similares. De hecho, es probable que Góngora hubiera observado con creciente interés lo que estaba ocurriendo por los mismos ańos en la poesía italiana más innovadora, fijándose especialmente en el "parlare ardito" del aristocrático poeta genovés Giovan Vincenzo Imperiale. Algunas voces autorizadas han señalado cómo los elementos característicos de Lo stato rustico se repiten en bastantes detalles de las Soledades (Cabani-Poggi 2013). Publicado por vez primera en 1607 y reimpreso en 1611 y 1613, el ambicioso poema descriptivo se extendía a lo largo de casi diecinueve mil versos, a la manera de un viaje en el que un "pellegrino errante" llamado Clizio descubre las maravillas del mundo campestre (cultivo y ganadería, pesca y caza) guiado por Euterpe.

Más allá de las coincidencias temáticas, interesa subrayar ahora la cuestión central de la novedad de estilo, ya que la abundancia de figuras y la modulación de la agudeza fascinaron a un amplio grupo de poetas y lectores. En las páginas liminares de la segunda edición del poema, que Imperiale dedicaba al "Gracioso lector", puede localizarse una valiosa reflexión sobre la elocución y las prácticas imitativas:

Aquel poeta en el que no se admiren con la pureza de la lengua, con el encanto de los conceptos y con la riqueza del número, las agudezas sutiles y chispeantes, las contraposiciones bizarras y las soberbias notas vivaces; aquel poeta que no enriquezca sus versos con palabras o frases tomadas ya del griego, ya del latín, innovadas o renovadas por él mismo con proporcionada forma apenas consideraría que fuera capaz de salirse de las filas del vulgo (Imperiale, Lo stato rustico, ed. O. Besomi, A. López-Bernasocchi y G. Sopranzi, II, p. 19). ${ }^{42}$

41. Traduzco el párrafo siguiente: "Non di meno loderei che talmente si pigliasse d'altri che si nascondesse l'imitatione [...]. Questo mi parrebbe sendo ben fatto che et le altrui parole, et le forme di dire, et le sentenze riceverebbono un altro grado che non si riconoscerebbono per quelle. Et questa è quella via che oltra modo mi sodisfarebbe".

42. Traduzco libremente el siguiente párrafo: "Quel poeta in cui no si ammirino, con la purità del dire, con la vaghezza dei concetti e con la ricchezza del numero, le arguzie frizzanti, i contrapposti leggiadri e le vivacità superbe; et il quale o di parole o di frasi, o dal greco o dal latino idioma 
La "audaz elocución" (o "parlare ardito") que defendía Imperiale como la mejor manera de escribir en los nuevos tiempos se apoya en un conjunto de "licencias" que afectan a las "metáforas", los "traslados" y los "asuntos". Ese conjunto de "atrevimientos" en todos los órdenes (conceptual y verbal) configuran los elementos que "sirven con más fuerza para elevar la nobleza del poeta con su manera soberbia" y consiguen alejarlo de los trillados senderos del vulgo (Imperiale, Lo stato rustico, ed. O. Besomi, A. López-Bernasocchi y G. Sopranzi, II, p. 19). Especialmente significativa resulta la ponderación de las "arguzie frizzanti" engastadas en el poema, ya que en esta troquelación acompaña a las "agudezas" del núcleo nominal un adjetivo que relaciona plásticamente una experiencia física con otra mental. Lo frizzante apunta en el plano material a lo 'efervescente' y 'burbujeante', a lo 'chispeante' como un buen vino espumoso, a aquello que en general 'provoca una sensación de sutiles pinchazos', mas desde el plano intelectivo también apela a lo 'sutil', a lo 'vivaz', a cuanto es capaz de estimular la imaginación y cosquillear el espíritu.

Imperiale propugnaba asimismo la imitación de los grandes maestros griegos y latinos, que proporcionan una cantera inmensa de "palabras" y "fórmulas" que cada poeta moderno con su gusto personal y su perspicacia deberá "innovar" o "renovar" valiéndose de oportunas modificaciones. Ahora bien, la tradición vernácula tiene igualmente cabida entre las fuentes, ya que se reconocerá pocas líneas después que entre los maestros modernos de la poesía "toscana" excedía a todos los demás Torquato Tasso y que en Lo stato rustico tuvo a gala "seguir" sus pasos "imitando" su limado estilo, que toma como firme base o punto de partida para alcanzar el novedoso "parlare ardito" a través de la sobreabundancia de figuras de ornato y la acumulación de conceptos. ${ }^{43}$

El símil de la rosa que Góngora incluye en las Soledades probablemente merezca con justicia los dos apelativos que Imperiale usara como valores dignos

tratte, o da lui con proporzionata forma, innovate o rinovate, non arricchisca le sue poesie, a pena giudicherei che dal volgo uscir potesse".

43. En 1647 Girolamo Ghilini acotaba en términos muy positivos el papel que había desempeñado Imperiale en la gestación del nuevo estilo secentista, ya que en su poema heroico había hallado "un nuovo modo di poetare spiritoso e tutto di metaforici ornamenti ripieno e dalla vaghezza dello stile e dalle invenzioni di bellissimi concetti acompagnato". Gracias a su "eminentissimo ingegno", con Lo Stato rustico, Imperiale había dado a luz un "parto" poético "del quale in simil genere il nostro secolo non è per goder cosa che all'eccellenza sua uguagliar si possa; ammirandosi in esso una grandissima copia di sentenze, di concetti, di colori, di lumi, di artifici a segno tale che devesi piu tosto chiamare una scuola di poeti che un poema" (Imperiale, Lo stato rustico, ed. O. Besomi, A. López-Bernasocchi y G. Sopranzi, I, p. 16). Ese mismo año, otro ingenio asociado a la veneciana Accademia degli Incogniti exaltaba sin tasa las innovaciones y bizarrías del ambicioso texto: "È certo che il suo eroico poema dello Stato rustico è opera per ogni rispetto così compita, che pochi libri ha l'antica età, non che la moderna, che le si possano anteporre. S'ammirano in questo divino poema la bellezza de' concetti, la vaghezza degli artifici, i lumi delle sentenze, la purità dello stile, la nobiltà delle invenzioni; et insomma epilogate tutte le eccellenze poetiche con tanta felicità" (ibidem). 
de elogio en un poeta moderno que conoce la tradición y la renueva desde dentro: ardito y frizzante. De hecho, se conserva una prueba elocuente de que el poeta cordobés se erigió en maestro aventajado, puesto que una vez puso en circulación una troquelación llamativa en las letras hispánicas, el testimonio de su éxito vendría dado por las imitaciones que a su vez generó. Otra de las cumbres de la poesía barroca en lengua española acogía una huella de la imagen floral inserta en el marco epitalámico, ya que sor Juana Inés de la Cruz quiso rendir homenaje al fragmento gongorino a través de la exaltación de la rosa engastada entre los versos 730-759 del Primero sueño. En un verdadero alarde de virtuosismo léxico, la décima musa novohispana empleó el mismo haz de isotopía que Góngora, reforzando en sus versos el conjunto de referentes asociados a la vestimenta y los tejidos:

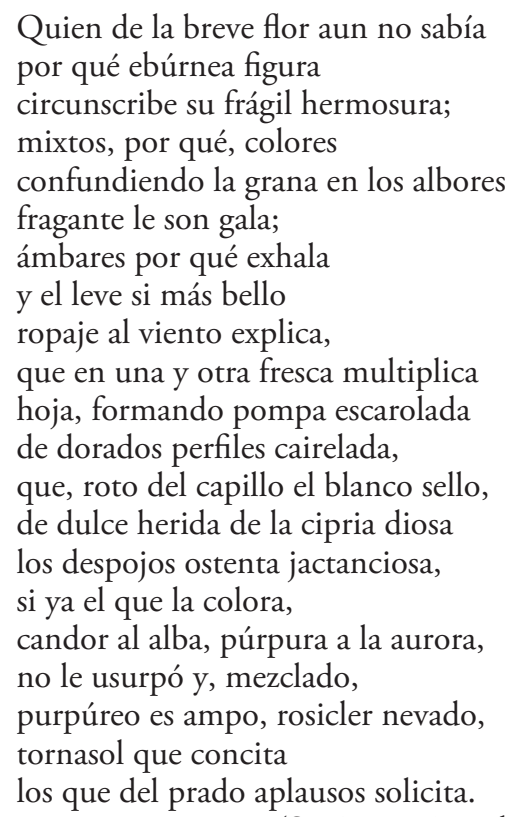

Quien de la breve flor aun no sabía por qué ebúrnea figura circunscribe su frágil hermosura; mixtos, por qué, colores confundiendo la grana en los albores fragante le son gala; ámbares por qué exhala y el leve si más bello ropaje al viento explica, que en una y otra fresca multiplica hoja, formando pompa escarolada de dorados perfiles cairelada, que, roto del capillo el blanco sello, de dulce herida de la cipria diosa los despojos ostenta jactanciosa, si ya el que la colora, candor al alba, púrpura a la aurora, no le usurpó y, mezclado, purpúreo es ampo, rosicler nevado, tornasol que concita los que del prado aplausos solicita.

(Sor Juana Inés de la Cruz, Primero Sueño, ed. Antonio Alatorre, pp. 184-185)

Frente a los cuatro elementos empleados por el cabeza de la escuela culta ("botón", "rizado", "cisuras", "cairela"), la aventajada discípula novohispana, amplía el listado hasta seis voces, llevando así a cabo un ejercicio de imitatio amplificativa ("grana”, "gala”, "ropaje”, "escarolada”, "cairelada”, "capillo"). 


\section{Un símil bajo el signo de la agudeza: la rosa como cifra simbólica}

Tal como ha podido constatarse en los apartados precedentes, la imagen de la rosa virginal que comienza a entreabrirse se vincula en los versos gongorinos a la exaltación de una hermosura femenina de tierna edad que comienza a dar sus primeros pasos por la estación de los amores. El símil de la Soledad primera formula esa identificación de manera palmaria y, posteriormente, la misma volverá a aparecer bajo forma de metáfora en otras composiciones gongorinas. ${ }^{44}$ También hemos tenido ocasión de apreciar cómo la actitud misma que caracteriza a la novia aldeana y el haz de rasgos que se le atribuye responden a un estereotipo cristalizado en la poesía de Occidente. De hecho, algunos comentaristas vinculaban difusamente los mismos al ámbito de la escritura epitalámica. Ciertamente, a la luz de tales datos podría pensarse que la motivación profunda que condujo a Góngora a la elección de la rosa en el símil referido a la novia aldeana no fue una cuestión azarosa, ni baladí. En efecto, la imagen del flos intactus o la rosa pudoris se inscribía en la milenaria tradición de la poesía nupcial, donde brillan los nombres de Safo y Catulo, de Estacio y Claudiano, de Pontano y Salmon Macrin, de Ariosto y Tasso, autores que en sus versos identificaban ya la flor con la novia, mas también con la virginidad propia de una doncella pudorosa que protege su virtud. ${ }^{45}$

44. Bastaría con espigar dos ejemplos ligeramente más tardíos, datados en 1618 y 1620 . Entre los versos de la Fábula de Píramo y Tisbe (vv. 273-278) el narrador se refiere en los términos siguientes a la heroína del epilio jocoserio, una vez acepta los amorosos avances de su pretendiente: "Amor, que los asistía, / el vergonzoso capullo / desnudó a la virgen rosa / que desprecia el tirio jugo; / abrió su esplendor la boba / y a seguillo se dispuso" (Góngora, Obras completas, ed. A. Carreira, I, p. 507). No mucho después, en el romance En la fuerza de Almería (vv. 13-20 y 33-40), concurre el mismo tipo de imagen floral, referido aquí a una beldad mora: "Celidaja, que en sus años / virgen era rosa, a quien / del verde nudo la Aurora / le desata el rosicler, / beldad ociosa crecía / en sus jardines tal vez, / al son de un laúd con ramas / que eran cuerdas de un laurel [...]. / Averiguando la halló / los días de casi tres / lustros de su tierna edad / aquel niño dios, aquel / fénix desnudo, si es ave, / pollo siempre, sin deber / segundas vidas al sol, / nieto del mar en la fe" (Góngora, Obras completas, ed. A. Carreira, I, pp. 547-548). Al cotejar estos pasajes con el parangón del pasaje nupcial de la obra inconclusa emerge algún pequeño dato, no carente de interés, por ejemplo la variatio estilística que lleva al poeta a referirse a la cubierta verde de los pétalos carmesíes con tres voces diversas: "verde botón", "vergonzoso capullo", "verde nudo". Cabe recordar también otro pasaje de la inconclusa canción que dedicara Al conde de Lemos en 1614. La imagen de la flor se emplea, significativamente, en el pasaje referido a las bodas del prócer y al instante de su unión amorosa con la novia en el lecho conyugal (vv. 49-52): "la tea de Himeneo [...] / te condujo ya al tálamo y la rosa / (que a las perlas del alba aun no se abría) / libaste en paz" (Góngora, Canciones y otros poemas en arte mayor, ed. J. M. Micó, p. 148). Siguiendo el código de la obscuridad honesta se vela metafóricamente en el pasaje el amplexo y la desfloración de la doncella. Para la identificación de Góngora como poeta que ostenta la máxima agudeza entre los ingenios de su tiempo, según la estimación de sus coetáneos, puede verse ahora Blanco y Ponce Cárdenas (2021).

45. De hecho, la equivalencia por analogía puede intervenir también en las comparaciones al igual que sucede en las metáforas. Recuérdese cómo Aristóteles en Poética XXI señalaba a propósito de esa última figura que si la vejez es a la vida como la tarde al día, puede afirmarse que la tarde es la "vejez 
El símil de la rosa no solo le permitía a Góngora conectar el pasaje con la escritura epitalámica de Grecia y Roma, de la Europa neolatina e Italia, sino que de algún modo le servía también de nudo simbólico en el que hacía converger varios hilos, como la exaltación de un encanto discreto y el elogio del silencio. ${ }^{46}$ Ese detalle lo supo apreciar Serrano de Paz en otro lugar de su commento:

En esta comparación igualó el Poeta las gracias, el silencio y la hermosura de la serrana a la rosa, que de todo esto es símbolo y así propio color de la vergüenza, madre de todos estos dones. Pero porque en la serrana están como abreviados y encogidos, que se muestran en poco muchos, por eso no hace la comparación a la belleza de la rosa ya toda abierta, porque si está patente da toda su hermosura sin encogimiento ni vergüenza, sino a la que aún encerrada dentro del botón muestra por las cisuras de él su bizarra púrpura en breves señas, significando en ellas cuanta hermosura encubre y encierra dentro (Serrano de Paz, f. 497v).

En el plano simbólico confluyen en un mismo punto las ideas de uerecundia y silentium, la pulchritudo y la gratia, quintaesenciadas en una ruborosa novia que permanece callada, mas no se muestra esquiva. Hasta donde se me alcanza, el erudito afincado en Oviedo fue el único entre los comentaristas que identificó ese otro vector de la simbología asociada a la flor purpúrea, a la rosa del silencio.

\section{Una pequeña consideración final}

No sin justicia se ha apuntado que el extenso pasaje consagrado por Góngora a la celebración de las bodas aldeanas en la Soledad primera conforma el mejor epitalamio de la España barroca (Blanco 2020). ${ }^{47}$ Dentro del mismo el genial

del día" y que la vejez es la "tarde de la vida". La formulación aplicada al símil podría esquematizarse del modo siguiente: si un elemento A es como un elemento B debido a determinados rasgos comunes que permiten establecer algún vínculo entre ellos, también puede predicarse que el elemento $B$ es como el elemento A, invirtiendo así los polos de la relación comparativa (A es como B / B es como A). Para la cuestión de la rosa y la muchacha virgen enlazadas comparativamente por la tonalidad roja (de los pétalos y el rubor vergonzoso) Lope de Vega ofrece así en la Descripción de La Tapada un bello ejemplo de símil que tiene como término real una rosa roja y como comparante una hermosa doncella que se sonroja (vv. 217-224): "La rosa, del delito temerosa / de haber herido con pungente espina / la blanca nieve, cuya sangre hermosa / por el castigo le dio color tan fina, / cual suele tierna virgen vergonzosa / las encendidas hojas determina / en la verde prisión, con luz tan breve / que a ser cometa del jardín se atreve" (Lope de Vega, Descripción de La Tapada, ed. A. Fadón, p. 108).

46. Sobre la milenaria tradición poética de la rosa como parangón de la virginidad, permítase remitir a Ponce Cárdenas (2021).

47. El conocimiento de la poesía epitalámica del Siglo de Oro ha experimentado un avance más que considerable a lo largo de los últimos años. Al conjunto de trabajos publicados por diferentes investigadores (baste espigar tres de los mismos: Martos Pérez 2012, Sánchez García 2013, Mateo Benito 2020), se suma ahora un libro modélico de Antonio Serrano Cueto (2019) y un número monográfico del Bulletin hispanique dedicado a la literatura nupcial en España (2020). 
escritor cordobés destiló una serie de fórmulas (la rosa y la abeja, los nudos de amor y la prolífica descendencia, la lluvia floral y el vuelo de los Cupidillos...) en las que se condensa la quintaesencia de numerosos modelos pertenecientes a una tradición milenaria que parte de Safo y llega hasta Torquato Tasso y Giovan Battista Marino.

A través del símil de la rosa Góngora consiguió abreviar las múltiples hermosuras de una imagen floral cantada durante centurias, apelando a través de la memoria poética al hipotexto remoto de Claudiano y a la fuente inmediata de Tasso. Con verdadero genio el escritor barroco acuñaba una troquelación novedosa que, a su vez, iba a legar a otros poetas de igual tenor culto, como Sor Juana Inés de la Cruz. La "beldad parlera" de la comparación encerraba a su vez la "gracia muda" y sutil de un estilo novedoso, de una audaz licencia que le permite situarse con voz personal y definida dentro de una cadena que se proyecta hacia el futuro. 


\section{Bibliografía}

Alonso, Dámaso, "Notas sobre el italianismo de Góngora”, en Obras completas, Madrid, Gredos, 1982, pp. 331-398.

Argensola, Bartolomé Leonardo, Rimas, ed. J. M. Blecua, Madrid, Espasa Calpe, 1974, 2 vols.

Ariosto, Ludovico, Orlando furioso, ed. L. Caretti, Turín, Einaudi, 1996, 2 vols. —, Orlando furioso, trad. J. de Urrea, ed. F. J. Alcántara, Barcelona, Planeta, 1988.

Blanco, Mercedes, Góngora heroico. Las Soledades y la tradición épica, Madrid, C.E.E.H., 2012.

-, "El venatorio estruendo: la oficina poética de Góngora y el tema de la caza", en El universo de Góngora. Orígenes, textos y representaciones, ed. J. Roses, Córdoba, Diputación de Córdoba, 2014, pp. 301-328.

-, Góngora o la invención de una lengua, León, Universidad de León, 2016 ².

—, "Góngora y la poética del epitalamio", Bulletin Hispanique, CXXII, 2 (2020: El epitalamio en España), pp. 479-516.

-, y Ponce Cárdenas, Jesús, "Sal y donaire sin comparación: la agudeza en el marco de la polémica”, en El universo de una polémica. Góngora y la cultura española del siglo XVII, ed. M. Blanco y A. Plagnard, Madrid-Fráncfort del Meno, Iberoamericana-Vervuert, 2021, pp. 331-375.

Cabani, Maria Cristina, y Poggi, Giulia, "Las Soledades e lo Stato rustico: una traccia da seguire", en La Edad del Genio: España e Italia en tiempos de Góngora, ed. B. Capllonch, S. Pezzini, G. Poggi y J. Ponce Cárdenas, Pisa, Edizioni ETS, 2013, pp. 87-109.

Caretti, Lanfranco, "Due restauri tassiani", en Studi sulle Rime del Tasso, Roma, Edizioni di Storia e Letteratura, 1950, pp. 197-217.

Carminati, Clizia, Tradizione, imitazione, modernità. Tasso e Marino visti dal Seicento, Pisa, Edizioni ETS, 2020.

Carreira, Antonio, Nuevos gongoremas, Córdoba, Universidad de Córdoba, 2021. CÉspedes, Baltasar de, Discurso de las letras humanas llamado El Humanista, ed. M. Comellas, Madrid, Real Academia Española, 2018.

Cisano, Giovanni, Poeti Toscani e ridotti sotto capi per ordine d'alfabeto da Giovanni Cisano. Con annotationi in molti luoghi di diversi, nelle quali si mostrano i colori et ornamenti poetici, i lumi delle dottrine e dell'arti sparsi per entro $i$ detti concetti et $i$ luoghi tolti da' Poeti Greci et Latini et felicemente imitati da' nostri. Oltre di ciò sotto i medesimi capi sono ridotti i concetti espresssi nelle Imprese raccolte in diversi volumi da diversi autori, con le loro dichiarationi e discorsi, Venecia, Evangelista Deuchino y Giovanni Battista Pulciani, 1610, 2 vols.

Claudiano, Obras, trad. Miguel Castillo Bejarano, Madrid, Gredos, 1993, 2 vols. —, Oeuvres. Poèmes politiques, ed. J. L. Charlet, Paris, Les Belles Lettres, 2002. —, Epitalami e Fescennini, ed. E. Bianchini, Florencia, Le Càriti Editore, 2004. Conde Parrado, Pedro, "Los Epitheta de Ravisius Textor y la Picta Poesis Ovi- 
diana de Niklaus Reusner en la Jerusalén conquistada y en otras obras de Lope de Vega", Anuario Lope de Vega, XXIII (2017), pp. 366-421.

—, "Las fuentes de erudición y el Humanismo Cristiano en la poesía de Lope de Vega: el comienzo del décimo canto del Isidro", en Lope de Vega y el Humanismo Cristiano, ed. Jesús Ponce Cárdenas, Madrid-Fráncfort del Meno, Iberoamericana-Vervuert, 2018, pp. 81-106.

—, "La erudición al servicio de la épica en el canto II del Isidro de Lope de Vega: la infernal Envidia contra el santo de Madrid", en Literatura y devoción en tiempos de Lope de Vega, ed. Jesús Ponce Cárdenas, Madrid-Fráncfort del Meno, Iberoamericana-Vervuert, 2019a, pp. 11-33.

-, "La adjetivación en la poesía de Góngora y los Epitheta de Ravisio Textor", Bulletin Hispanique, CXXI, 1 (2019b), pp. 263-312.

—, "Teología de arte menor: el Pseudo-Dionisio y los padres apostólicos en el Isidro y en otras obras de Lope de Vega", en La escritura religiosa en Lope de Vega: entre lírica y epopeya, ed. Jesús Ponce Cárdenas, Madrid-Fráncfort del Meno, Iberoamericana-Vervuert, 2020, pp. 123-159.

Covarrubias, Sebastián de, Tesoro de la lengua castellana o española, Barcelona, Alta Fulla, 1998.

Díaz de Rivas, Pedro, Anotaciones a la Segunda Soledad, ed. Melchora Romanos y Patricia Festini, París, Sorbonne Université, 2017, en línea, <https:// obvil.sorbonne-universite.fr/corpus/gongora/html/1617_soledad-segundadiaz.html>.

—, Anotaciones al Polifemo, B.N.E. Ms. 3906.

—, Anotaciones y defensas a la Primera Soledad, BNE, Ms. 3726.

-, Discursos apologéticos por el estilo del Polifemo y Soledades, obras poéticas del Homero de España, don Luis de Góngora y Argote [1624], BNE, Ms. 3726.

Estacio, Silvae, ed. y trad. R. Shackleton Bailey, Cambridge-Londres, Harvard University Press, 2003.

—, Silvas, trad. F. Torrent Rodríguez, Madrid, Gredos, 1995.

—, La Tebaida de Publio Papinio Estacio traducida en verso castellano por el licenciado Juan de Arjona, Madrid, Librería de la Viuda de Hernando y Compañía, 1888, 2 vols.

—, Tebaide, ed. y trad. G. Faranda Villa, Milán, Biblioteca Universale Rizzoli, 1998, 2 vols.

Étienvre, Jean-Pierre, Márgenes literarios del juego. Una poética del naipe (siglos XVI-XVIII), Londres, Tamesis Books, 1990.

Fernández de Córdoba, Francisco (Abad de Rute), Examen del Antídoto o Apología por las Soledades de don Luis de Góngora contra el autor del Antídoto, ed. Matteo Mancinelli, Córdoba, Almuzara, 2019.

García Jiménez, Pedro Iván, Las Rimas (1627) de Salcedo Coronel: edición y estudio, Tesis doctoral, Sevilla, Universidad de Sevilla, 2013.

Gates, Eunice Joiner, Documentos gongorinos, Ciudad de México, El Colegio de México, 1960. 
Góngora, Luis de, Canciones y otros poemas en arte mayor, ed. J. M. Micó, Madrid, Espasa Calpe, 1990.

—, Décimas, ed. S. Pezzini, Alessandria, Edizioni dell'Orso, 2018.

—, Fábula de Polifemo y Galatea, ed. J. Ponce Cárdenas, Madrid, Cátedra, $2019^{6}$.

—, Obras completas, ed. A. Carreira, Madrid, Biblioteca Castro, 2000, 2 vols.

—, Romances, ed. A. Carreira, Barcelona, Quaderns Crema, 1998, IV vols.

—, Soledades, ed. R. Jammes, Madrid, Castalia, 1994.

- Soledades comentadas por don García de Salcedo Coronel, Madrid, Imprenta Real, 1636.

—, Sonetos, ed. J. Matas Caballero, Madrid, Cátedra, 2019.

—, Teatro completo, ed. L. Dolfi, Madrid, Cátedra, 2015.

Góngora vindicado. Soledad primera ilustrada y defendida, ed. M. J. Osuna Cabezas, Zaragoza, Prensas Universitarias de Zaragoza, 2009.

Homero, Odissea Homeri per Raphaelem Volaterranum in latinum conuersa, Romae, Per Iacobum Mazochium, 1510.

—, Odisea, trad. J. M. Pabón, Madrid, Gredos, 1993.

Horacio, Arte poética, trad. y ed. Juan Antonio González Iglesias, Madrid, Cátedra, 2012.

Imperiale, Giovan Vincenzo, Lo stato rustico, Génova, Giuseppe Pavoni, 1611.

-, Lo stato rustico, ed. O. Besomi, A. López-Bernasocchi y G. Sopranzi, Roma, Edizioni di Storia e Letteratura, 2015, 2 vols.

Jammes, Robert, "Función de la retórica en las Soledades", en La silva, ed. Begoña López Bueno, Sevilla, Universidad de Sevilla, 1991, pp. 213-233.

Jáuregui, Juan de, Antídoto contra la pestilente poesía de las Soledades, ed. J. M. Rico García, Sevilla, Universidad de Sevilla, 2002.

Ly, Nadine, Lecturas gongorinas. De gramática y poesía, Córdoba, Universidad de Córdoba, 2020.

Marino, Giovan Battista, Rime. Parte seconda. Madriali e canzoni, Venecia, Giovan Battista Ciotti, 1602.

Martos Pérez, María Dolores, "Panegíricos nupciales a las bodas del IX y X duque de Medina Sidonia: mecenazgo, propaganda y renovación estética", en El duque de Medina Sidonia: mecenazgo y renovación estética, ed. José Manuel Rico, Luis Gómez Canseco y Pedro Ruiz Pérez, Huelva, Universidad de Huelva, 2012, pp. 289-298.

Mateo Benito, Daniel, "Hoy es el sacro y venturoso día: un centón epitalámico de Vera Tassis”, Creneida, núm. 8 (2020), pp. 162-220.

Montagnani, Cristina, "Negli anni acerbi tuoi purpurea rosa: occasioni variantistiche”, Studi Tassiani, XXXIII (1985), pp. 89-106.

Parthenio, Bernardo, Della imitatione poetica, Venecia, Appresso Gabriel Giolito de' Ferrari, 1560.

Pellicer de Salas y Tovar, José de, Lecciones solemnes a las obras de don Luis de Góngora y Argote, Madrid, Imprenta del Reino, 1630; edición facsímil, Hildesheim-Nueva York, Georg Olms Verlag, 1971. 
Ponce Cárdenas, Jesús, Evaporar contempla un fuego helado. Género, enunciación lírica y erotismo en una canción gongorina, Málaga, Universidad de Málaga, 2006.

—, "El símil épico en el Polifemo: función y alcance de una figura elocutiva", en Cinco ensayos polifémicos, Málaga, Universidad de Málaga, 2009, pp. 241-369.

—, "De nombres y deidades: claves piscatorias en la Soledad segunda", Caliope, XVIII, 3 (2013), pp. 85-125.

—, "Géneros y modelos en las Soledades: la epopeya didáctica", en El universo de Góngora: orígenes, textos y representaciones, ed. J. Roses, Córdoba, Diputación de Córdoba, 2014a, pp. 249-279.

—, "Del elogio consular al preludio amoroso: el vuelo del Fénix en Claudiano, Tasso y Góngora", en Manipulus studiorum en recuerdo de la profesora Ana María Aldama Roy, Madrid, Escolar y Mayo, 2014b, pp. 815-829.

—, La imitación áurea. Cervantes, Quevedo, Góngora, Paris, Éditions Hispaniques, 2016.

—, "Pontano y Góngora: ecos de la Lepidina en la Soledad primera", Bulletin Hispanique, CXXII, 2 (2020: El epitalamio en España), pp. 517-541.

—, "Rosae sub signo: anotaciones a un símil clásico", Translat Library, III (2021), pp. 1-19, en línea, <https://scholarworks.umass.edu/tl/vol3/iss1/4/>.

Pontano, Baiae, ed. y trad. Rodney G. Dennis, Cambridge-Londres, Harvard University Press, 2006.

Quevedo, Francisco de, Obras festivas, ed. P. Jauralde Pou, Madrid, Castalia, 1984.

Salazar Mardones, Cristóbal de, Ilustración y defensa de la fábula de Píramo y Tisbe, Madrid, Imprenta Real, 1636.

SÁnchez García, Encarnación, "Ecos gongorinos en la Nápoles del III duque de Alcalá: el Epitalamio de Salcedo Coronel en honor de María Enríquez de Ribera y Luis de Aragón y Moncada", en Lingua spagnola e cultura ispanica a Napoli fra Rinascimento e Barocco. Testimonianze a stampa, Nápoles, Tullio Pironte Editore, 2013, pp. 241-272.

Serrano Cueto, Antonio, El epitalamio neolatino. Poesía nupcial y matrimonio en Europa (siglos XV y XVI), Alcañiz-Lisboa, Instituto de Estudios Humanísticos-Centro de Estudos Clássicos, 2019.

Serrano de Paz, Manuel, Commentarios a las Soledades del grande poeta don Luis de Góngora, RAE, Ms. 114-115, 2 vols.

Sor Juana Inés de la Cruz, Primero Sueño, ed. Antonio Alatorre, y Luis de Góngora, Soledades, ed. Antonio Carreira, México, Fondo de Cultura Económica, 2010.

STURM, Johannes, De imitatione oratoria libri tres, cum scholis eiusdem authoris, antea numquam in lucem editi, Argentorari, Imprimebat Bernhardus Iobinus, 1574.

Tanabe, Madoka, "Tradición e innovación en el epitalamio de la primera Soledad", Analecta Malacitana Electrónica, núm 30 (2011), pp. 59-89. 
Tasso, Torquato, Gerusalemme liberata, ed. L. Caretti, Milán, Arnoldo Mondadori Editore, 1992.

—, Prose, ed. Ettore Mazzali, Milán-Nápoles, Riccardo Ricciardi Editore, 1959.

—, Rime, ed. B. Basile, Roma, Salerno Editrice, 1994, 2 vols.

—, Rime eteree, ed. R. Pestarino, Parma, Fondazione Pietro Bembo-Ugo Guanda Editore, 2013.

—, Teatro, ed. Angelo Solerti, Bolonia, Ditta Nicola Zanichelli, 1895.

Tibulo, Tibulli aliorumque carminum libri tres, ed. J. P. Postgate, Oxford, Clarendon Press, 1968.

—, Elegías, trad. Arturo Soler Ruiz, Madrid, Cátedra, 1993.

Vega, Lope de, La Dorotea, ed. Edwin S. Morby, Madrid, Castalia, 2001.

—, Descripción de La Tapada, ed. Alberto Fadón, Madrid, Giardini di Bomarzo, 2020.

Vilanova, Antonio, Las fuentes y los temas del Polifemo de Góngora, Barcelona, PPU, 1992².

Virgilio, Eneida, trad. J. de Echave Sustaeta, Madrid, Gredos, 1992.

Visentini, Elena, Il regno di Venere nell' Epithalamium de nuptiis Honorii et Mariae: fonti e fortuna, Padua, Università di Padova, 2018. 